\title{
Low-cost, simple and eco-friendly biosynthesis of Ce02-NPs using extract of Pelargonium hortorum for the photocatalytic and antioxidant applications
}

Ali Ganbarianzade Mahabadi

Islamic Azad University

Abbas Mirzakhani

Agricultural Research, Education and Extension Organization (AREEO)

Amir Azizi ( $\square$ a-azizi@araku.ac.ir)

Faculty of Science, Arak University https://orcid.org/0000-0003-2741-6797

Saied Chavoshi

Arak Branch, Islamic Azad University

Shahab Khaghani

Arak Branch, Islamic Azad University

\section{Original Research Full Papers}

Keywords: Phytochemical composition, Pelargonium hortorum extracts, Biosynthesis, $\mathrm{CeO} 2$-NPs, Practical application

Posted Date: February 1st, 2021

DOI: https://doi.org/10.21203/rs.3.rs-161201/v1

License: (c) (i) This work is licensed under a Creative Commons Attribution 4.0 International License.

Read Full License 
Low-cost, simple and eco-friendly biosynthesis of $\mathrm{CeO}_{2}-\mathrm{NPs}$ using extract of Pelargonium hortorum for the photocatalytic and antioxidant applications

\section{A. Ganbarianzade Mahabadi a,}

Address and Affiliation: Department of Horticulture Science, Arak Branch, Islamic Azad University, Arāk, Iran

Email: ganbariyanali@gmail.com

\section{A. Mirzakhani ab,}

Address and Affiliation: Horticulture Crops Researcher Department, Markazi Agricultural and Education center, Agricultural Research, Education and Extension Organization (AREEO), Arak, Iran

Email: Mirz51@yahoo.com

3. A. Azizi ${ }^{\mathrm{c}^{*}}$ (Corresponding Author),

Address and Affiliation: Department of Chemistry, Faculty of Science, Arak University, Arak, Iran

Postal code: $38156-8-8138$

Tel.: +98 86 32627536; fax: +98 8632777400

Email: a-azizi@araku.ac.ir

\section{S. Chavoshi ${ }^{d}$}

Address and Affiliation: Department of Agronomy and Plant Breeding, Arak Branch, Islamic Azad University, Arāk, Iran

Email: s-chavoshi@iau-arak.ac.ir

\section{Sh. Khaghani ${ }^{d}$}

Address and Affiliation: Department of Agronomy and Plant Breeding, Arak Branch, Islamic Azad University, Arāk, Iran

Email: shahab.khaghani@gmail.com 


\section{Abstract}

In this paper, firstly the phytochemical composition in the aqueous extract of Pelargonium, growing wildly in the center of Iran, was studied. Folin-Ciocalteu and Aluminum chloride methods and the GC/MS technique were used to determine the total phenolic, flavonoid contents, and volatile constituents in the extract, respectively. The amounts of the total phenolic and flavonoid contents in the extract were found to be $136.5 \mathrm{mg} \mathrm{GA} / \mathrm{g}$ and $63.9 \mathrm{mg} \mathrm{RU} / \mathrm{g}$, respectively. Twenty-one compounds, representing 15 (about 80.0\%) of the total volatile constituents were identified. The main components of the volatile constituent were $\alpha$-pinene (25.28\%) and fenchyl acetate (20.63\%). Secondly, a fast, simple, and eco-friendly biosynthesis of cerium oxide nanoparticles $\left(\mathrm{CeO}_{2}-\mathrm{NPs}\right)$ were investigated using the extract of Pelargonium as a natural reducing and stabilizing agent. Several advance techniques such as UltravioletVisible (UV-Vis) spectroscopy, X-ray diffraction (XRD), Scanning electron microcopy (FESEM), Dynamic light scattering (DLS), and Brunaure Emmett-Teller (BET) were used for the analysis and characterization of the synthesized nanoparticles. The results of the characterization analysis showed that the prepared nanoparticles were spherical in shape, with an average size of $28 \mathrm{~nm}$ and zeta potential of $-25.8 \mathrm{mV}$, and had $33.84 \mathrm{~m}^{2} / \mathrm{g}$ BET surface area, $9.31 \mathrm{~nm}$ mane diameter pore, and a total pore volume of $0.078 \mathrm{~cm}^{3} / \mathrm{g}$. Finally, the practical applications including the antioxidant and photocatalyst activity of the biosynthesized $\mathrm{CeO}_{2}$ NPs were evaluated. An analysis of antioxidant and catalytic activities showed that the biosynthesized $\mathrm{CeO}_{2}$-NPs have a good ability of scavenging of 2,2-diphenyl-1-picrylhydrazyl (DPPH) free radical with the $\mathrm{IC}_{50}$ value of $42.7 \mu \mathrm{g} / \mathrm{mL}$ and also good reduction ability of hexavalent chromium $\{\mathrm{Cr}(\mathrm{VI})\}$ ions with a reduction efficiency of $94 \%$ in an aqueous solution containing $10 \mathrm{mg} / \mathrm{L}$ of $\mathrm{Cr}(\mathrm{VI})$ of ion with natural $\mathrm{pH}$ of 5.5 and $\mathrm{CeO}_{2}-\mathrm{NPs}$ dose of $200 \mathrm{mg} / \mathrm{L}$ during $60 \mathrm{~min}$. 
Keywords: Phytochemical composition, Pelargonium hortorum extracts, Biosynthesis, $\mathrm{CeO}_{2}$ -NPs, Practical application 


\section{Introduction}

Cerium oxide nanoparticle $\left(\mathrm{CeO}_{2}-\mathrm{NPs}\right)$ is one of the important metal oxides that could be used in optical, medical, and catalytical applications for its unique physicochemical properties including biocompatibility, high stability, and special surface chemistry [1-3]. $\mathrm{CeO}_{2}-\mathrm{NPs}$ are usually synthesized via chemical methods, which mostly employ toxic reducing agents, posing various threats to the environment. In addition, the $\mathrm{CeO}_{2}$ prepared with these methods is toxic and unstable, reducing its efficiency [4,5]. Accordingly, in recent decades, a safe, non-toxic, eco-friendly, and low cost approach, known as biological (green) synthesis, is used by researchers for production of metal oxide nanoparticales, including $\mathrm{CeO}_{2}$ [6-8]. This approach employs various biological resources such as plants, microbes, or any other biological derivative (primary and secondary metabolites) believed to lead to reduction and stabilization. Studies show that these compounds are polyphenols, flavonoids, tannic acid, terpenoids, carbohydrates, amines, enzymes, etc., which function as natural antioxidants [1,9]. In general, the high antioxidant activity of the plant or microorganism results in an extract or any other biological derivative with high reducing capacity, which in turn increases the efficiency of the synthesized nanoparticle [9].

Numerous published studies are available on biological synthesis of $\mathrm{CeO}_{2}-\mathrm{NPs}$ using plant extracts or other biological derivatives for multipurpose applications. In these studies, green synthesized $\mathrm{CeO}_{2}$-NPs have been mostly examined for biomedical purposes such as antimicrobial, anticancer, anti-larvicidal, and antioxidant therapies and photocatalytic degradation of organic compound applications [2-11]. However, there are few studies dealing with an antioxidant and the photocatalytic role of $\mathrm{CeO}_{2}-\mathrm{NPs}$ synthesized by the green method on heavy metal ions of wastewater treatment. For example, Xiao et al. reported an excellent photocatalytic activity for $\mathrm{CeO}_{2} / \mathrm{BiOIO}_{3}$ heterojunction with oxygen vacancies and $\mathrm{Ce}^{4+} / \mathrm{Ce}^{3+}$ redox and its application in removal of the $\mathrm{Hg}^{2+}$ ion [12]. Balakumar et al. (2019) used an 
ultrasound-assisted method to improve the structure of $\mathrm{CeO}_{2} @$ polyprrole core-shell nanosphere and its photocatalytic reduction of $\mathrm{Cr}(\mathrm{VI})$ [13]. Kashinath et al reported microwave mediated synthesis and characterization of $\mathrm{CeO}_{2}-\mathrm{GO}$ hybrid composite for removal of chromium ions and their antibacterial efficiency [14]. Saravanakumar et al. reported construction of novel $\mathrm{Pd} / \mathrm{CeO}_{2} / \mathrm{g}-\mathrm{C}_{3} \mathrm{~N}_{4}$ nanocomposites as efficient and visible-light photocatalysts for hexavalent chromium detoxification [15]. In another study, multi-functional properties of ternary $\mathrm{CeO}_{2} / \mathrm{SnO}_{2} / \mathrm{rGO}$ nanocomposites, including visible light driven photocatalyst and heavy metal $\left(\mathrm{Cd}^{2+}\right.$ and $\left.\mathrm{Pb}^{2+}\right)$ removal were reported by Priyadharsanet al. [16].

The aim of this research is biological synthesis of $\mathrm{CeO}_{2}-\mathrm{NPs}$ using aqueous extracts of Pelargonium hortorum, a growing plant in Iran, as a natural reducing and stabilizing agent. Pelargonium belongs to the Geraniaceae family with about 300 species, mostly known as an ornamental plant; however, it is also used in the manufacture of herbal medicines for its unique medicinal properties [17]. The literature includes studies using several flavonoids in extracts extracted from geranium, including quercetin 3-O-glucoside, quercetin 3-O-pentose, isorhamnetin aglycone, kaempferol 3-O-, kaempferol 3-O-glucoside, kaempferol 3,7-di-Oglucoside, rhamnoside-glucoside, quercetin 3-O-pentoside-glucoside, myrisetin 3-Oglucoside-rhamnoside, and quercetin 3-O-rhamnoside-glucoside [17,18]. These compounds (polyphenolic compounds including flavonoids) act as natural reducing agents in extracts and it is predicted that these extracts could act as a potent green and non-toxic reluctant in synthesis of nanoparticles $[9,18]$. There is paucity of research on the use of geranium extract for synthesis of metal oxides. Most of the studies mentioning the ability of geranium extract as a reducing agent reported synthesis of noble metals nanoparticles such as silver and gold and their application in medicine [18-22]. The review of the literature carried out in this study indicated that so far there is no phytochemical study of Pelargonium hortorum and its use for 
biosynthesis of pure $\mathrm{CeO}_{2}$-NPs for antioxidant and photocatalytic applications, and especially in the photocatalytic reduction of hexavalent chromium, $\mathrm{Cr}(\mathrm{VI})$, ions.

Chromium ion has been classified as an important water pollutant, which mostly appears in form of $\mathrm{Cr}(\mathrm{VI})$ and $\mathrm{Cr}(\mathrm{III})$ states in aquatic environments. $\mathrm{Cr}(\mathrm{VI})$ is widely found in wastewater originating from many industries dependent on chromium; thus, concentration of $\mathrm{Cr}(\mathrm{VI})$ in the effluent of these industries is higher than the allowable limit extractable $(0.1 \mathrm{mg} / \mathrm{L})$ in surface waters [23-25]. According to the literature, ions of $\mathrm{Cr}(\mathrm{VI})$ are more toxic than $\mathrm{Cr}(\mathrm{III})$ ions, thus, more dangerous to the environment and health of living organisms; therefore, reduction of $\mathrm{Cr}(\mathrm{VI})$ to $\mathrm{Cr}(\mathrm{III})$ ions could be a suitable strategy for reducing the risks of $\mathrm{Cr}(\mathrm{VI})$ ions and easy separation of this ion from water. Given solubility of $\mathrm{Cr}(\mathrm{VI})$ ions in water, it is difficult to remove them from water whereas $\mathrm{Cr}$ (III) ions can be easily precipitated by alkalizing the solution and separated in solid sludge form [ 26,27].

To the best of my knowledge, this study is the first report on chemical composition of the extract of Pelargonium hortorum, grown in central Iran, looking for a simple and eco-friendly biosynthesis of pure cerium oxide $\left(\mathrm{CeO}_{2}-\mathrm{NPs}\right)$ using this extract as a green bioreducing reagent. In this regard, the phytochemical composition including total phenolic, flavonoid, and volatile constituents in the extract of Pelargonium hortorum was determined by FolinCiocalteu and aluminum chloride methods and GC/MS technique, respectively. In addition, the microstructure, optical properties, and some other properties of the biosynthesized $\mathrm{CeO}_{2}-\mathrm{NPs}$ were characterized by using various advanced techniques including Ultraviolet-Visible (UVVis) spectroscopy, X-ray diffraction (XRD), Dynamic light scattering (DLS), and Brunaure Emmett-Teller (BET). Moreover, the performance of the biosynthesized nanoparticles was used in 2,2-diphenyl-1-picrylhydrazyl (DPPH) free radical scavenging and photocatalytic reduction of $\mathrm{Cr}(\mathrm{VI})$ ions as the model metal ion.

\section{Materials and method}




\subsection{Materials}

The Pelargonium hortorum plants used for the study were collected from the center of Iran (Arak, Markazi province) at the beginning of Aug 2020 and were used after they were approved by the herbarium expert of the Botanical Garden of Arak University. The materials applied in this study were purchased from Merck and Aldrich chemical companies with high purity and used as such, without further purification. For example, Cerium nitrate purity $\geq 99.0 \%$ was purchased from Aldrich. Potassium dichromate (>99.9\%), 1,5-diphenylcarbohydrazide (DPC) purity $>99.0 \%$, for metal indication, n-hexane (purity >99\%), anhydrous sodium sulfate (>98.5\%), hydrochloric acid purity $>36 \%$, sodium hydroxide $(>97 \%)$, methanol (purity $>99 \%$ ), and ethanol with purity of $>99.9 \%$, were all Merck products. Folin-Ciocalteu reagent was purchased from Sigma-Aldrich Corporation. Gallic acid (GA) with purity of $>98 \%$, sodium carbonate (purity $>99 \%$ ), rutin (RU) with purity of $>97 \%$, and aluminum chloride (purity $>98.9 \%$ ) were also purchased from Merck. Double distilled water with conductivity of less than $0.2 \mu \mathrm{S} / \mathrm{cm}$ was used in this study for preparation of all of the experiment solutions.

\subsection{Method}

\subsubsection{Preparation of the Pelargonium hortorum extract}

For this purpose, first some parts of fresh leaves and flowers of Pelargonium hortorum were selected and washed. Then $10 \mathrm{~g}$ of this material were carefully weighed and transferred to a $250 \mathrm{~mL}$ beker containing $100 \mathrm{~mL}$ of double distilled water. The prepared mixture was heated below the boiling temperature for 1 hour. Finally, the prepared solution was cooled and filtered and then stored in a dark bottle at $4{ }^{\circ} \mathrm{C}$ until use in the next steps.

\subsubsection{Determination of the phytochemical composition}

Total phenolic and flavonoid contents of the Pelargonium hortorum aqueous extract after addition of Folin-Ciocalteu and aluminum chloride as the coloring agents were determined by 
a UV-Vis spectrophotometer at $\lambda_{\max }=765 \mathrm{~nm}$ and $\lambda_{\max }=415 \mathrm{~nm}$, respectively $[28,29]$. Briefly, $0.5 \mathrm{~mL}$ of each diluted extract was mixed with $0.5 \mathrm{~mL}$ of each reagent (Folin-Ciocalteu reagent in presence of sodium carbonate or 5\% aluminum chloride methanolic solution). After 30 min, the absorbance rates were read at $765 \mathrm{~nm}$ and $415 \mathrm{~nm}$, respectively, for determining the total phenolic and favonoid contents. To determine the total phenolic and flavonoid contents by standard calibration curves of gallic acid (GA) and rutin (RU) was used and the results were expressed as milligrams of GA and RU equivalent per gram of each extract (mg GA/g and mg $\mathrm{RU} / \mathrm{g})[28,29]$.

The volatile compounds in the Pelargonium hortorum aqueous extracts were isolated using Syringe to Syringe dispersive liquid-phase microextraction (SS-DLPME) method [30]. Nhexane was applied as the extraction solvent. Briefly, $2 \mathrm{~mL}$ of aqueous extract were put in a Syringe and then mixed with $2 \mathrm{~mL}$-hexane solvent. After agitation for $10 \mathrm{~min}, 2 \mathrm{~mL}$ of the organic solvent was separated by decantation, dried with anhydrous sodium sulfate, and then concentrated to $1 \mathrm{~mL}$ by evaporation under vacuum at $50^{\circ} \mathrm{C}$. Finally, the concentrated product was injected into the chromatograph coupled with mass detector \{ GC/MS (GC: HP 6890, MS: HP 5973), column (HP5-MS, $30 \mathrm{~m} \times 0.25 \mathrm{~mm}$ fused silica capillary column) $\}$ to determine the volatile compounds.

\subsubsection{Biosynthesis of $\mathrm{CeO}_{2}-\mathrm{NP}$}

The biological synthesis of $\mathrm{CeO}_{2}-\mathrm{NP}$ was performed according to the common methods reported in the literature [6-8] yet with some modifications and optimization in the synthesis effectiveness variable, including the cerium salt concentration, extract volume, temperature, and time. Optimizations in the process of synthesizing $\mathrm{CeO}_{2}-\mathrm{NP}$ was based on achieving the highest absorption spectra intensity within $300-330 \mathrm{~nm}$ (due to charge transfer from $\mathrm{O}_{2} \mathrm{P}$ to

$\mathrm{Ce}_{4 \mathrm{f}}$ orbitals) [31], which was measured and recorded by a UV-Vis spectrophotometer. Under optimum condition, $20 \mathrm{~mL}$ of aqueous extract of Pelargonium hortorum, as the reducing agent, 
was added to $80 \mathrm{~mL}$ of $0.1 \mathrm{M}$ cerium solution $\left(2.91 \mathrm{~g}\right.$ of $\mathrm{Ce}\left(\mathrm{NO}_{3}\right)_{2} .6 \mathrm{H}_{2} \mathrm{O}$ salt were dissolved in $100 \mathrm{~mL}$ double distilled water). Then the solution was mixed by magnetic stirring for $2 \mathrm{~h}$ at $80^{\circ} \mathrm{C}$ and the water was removed until a whitish-brown gel was obtained, which indicated the biosynthesis of cerium nanoparticale compounds [32]. The obtained gel was washed several times with double distilled water and ethanol and then was air dried in an oven at $70{ }^{\circ} \mathrm{C}$ for 1 h. Finally, the dried biosynthesized produced was calcined at $400 \mathrm{C}$ for $2 \mathrm{~h}$.

\section{3. $\mathrm{CeO}_{2}-\mathrm{NPs}$ characterization}

A UV-Vis spectrophotometer (dynamic HaloXB-10) was used to confirm the successful formation of $\mathrm{CeO}_{2}$-NPs during the biosynthesis method and also to determine the optical properties of the $\mathrm{CeO}_{2}$-NPs. Fourier-transform infrared spectroscopy (FTIR Bruker alpha Pusing the $\mathrm{KBr}$ pellets) was used to determine the functional groups present in the synthesized $\mathrm{CeO}_{2}$-NPs within the range of $4000-400 \mathrm{~cm}^{-1}$. In order to determine the phase and the crystal structure of the synthesized $\mathrm{CeO}_{2}-\mathrm{NPs}$, a separate XRD (ITAL-Structures-APD 2000) with Cu Ka radiation X-ray source was used. To analyze the distribution size and zeta potential of $\mathrm{CeO}_{2}$ NPs, a DLS analyzer (HORIBA SZ-100) was applied. Field emission scanning electron microscopy (FESEM, TESCAN, and Mira III) was employed to determine the morphology of $\mathrm{CeO}_{2}$-NPs. The EBT $\mathrm{N}_{2}$-adsorption (BELSORP, Mini II) was carried out to determine the surface properties of the biosynthesized $\mathrm{CeO}_{2}$-NPs.

\subsubsection{Antioxidant activity}

The free radical scavenging activity of the Pelargonium hortorum aqueous extract and the biosynthesized $\mathrm{CeO}_{2}$-NPs was determined by the percentage of 2,2-diphenyl-1-picrylhydrazyl (DPPH) free radical scavenging efficiency [33]. Briefly, $2 \mathrm{~mL}$ of either of the Pelargonium hortorum aqueous extract or $\mathrm{CeO}_{2}-\mathrm{NPs}$ solution in different concentrations $(5-100 \mu \mathrm{g} / \mathrm{mL}$ in methanol) was added to $3 \mathrm{~mL}$ of methanolic DPPH solution, kept for $30 \mathrm{~min}$ in dark, and then 
centrifuged. After that, the absorbance of the supernatant at $517 \mathrm{~nm}$ was determined using a UV-Vis spectrophotometer. The absorbance at $517 \mathrm{~nm}$ of methanolic DPPH solution without aqueous extract or $\mathrm{CeO}_{2}-\mathrm{NPs}$ was also analyzed for control. Percentages of radical scavenging

$(\% \mathrm{SCV})$ were calculated as $\% S C V=\frac{A_{0}-A_{S}}{A_{0}} \times 100$

where $A_{0}$ is the DPPH control absorbance and $A_{s}$ is the DPPH absorbance with aqueous extract or $\mathrm{CeO}_{2}-\mathrm{NPs}$.

\subsection{Photocatalytic activity}

The photocatalytic reduction of the hexavalent chromium ions from aqueous solutions was studied to investigate the photocatalytic activity of the biosynthesized $\mathrm{CeO}_{2}-\mathrm{NPs} .10 \mathrm{mg} / \mathrm{L}$ of the $\mathrm{Cr}(\mathrm{VI})$ ions solution with natural $\mathrm{pH}$ of 5.5 was used as a model pollutant to determine the photocatalytic activity. $200 \mathrm{mg}$ of $\mathrm{CeO}_{2}-\mathrm{NPs}$ as the photocatalyst was applied for reduction of 1.5 liters solution. A $250 \mathrm{~W}$ mercury lamp with the maximum emission at wavelength of 365 $\mathrm{nm}$ (inside quartzes tube) placed in the center of a double-walled glass photo-reactor with $2 \mathrm{~L}$ capacity was used for the reduction process. The content of the reactor was stirred by a mechanical stirrer and its temperature was controlled by passing water through the outer jacket of the reactor. A UV light source was turned on after $30 \mathrm{~min}$ of stirring the solution (in order to evaluate the effect of surface absorption, the solution was stirred for $30 \mathrm{~min}$ in darkness). Sampling was done every $10 \mathrm{~min}$. After centrifuging and photocatalyst separation, the residual concentration of $\mathrm{Cr}(\mathrm{VI})$ ions was analyzed with the appropriate calibration data by colorimetry method with 1,5-diphenyl carbazide (DPC) in acidic solution at $\lambda$ max $=542 \mathrm{~nm}$ using UV-Vis spectrophotometer [34]. Then the reduction efficiency $(R E)$ was calculated by the following equation:

$\% R E=\frac{[C]_{0-}[C]_{t}}{[C]_{0}} \times 100$ 
where $[C]_{0}$ and $[C]_{t}$ are initial and appropriate time concentrations of $\mathrm{Cr}(\mathrm{VI})$ ions, respectively.

\section{Results and discussion}

\subsection{Total phenolic and flavonoid content}

Assessment of the results of the study regarding the presence of polyphenolic compounds in the Pelargonium hortorum extract, including polyphenols and flavonoids compounds, which were performed by Folin-Ciocalteu and ammonium chloride methods, respectively, showed that the amounts of polyphenols and flavonoids compounds in the extract are $136.5 \mathrm{mg}$ of $\mathrm{GA} / \mathrm{g}$ extract and $63.9 \mathrm{mg}$ of RU/g extract, respectively. Studies in the literature have reported that presence of polyphenolic compounds in derivatives extracted from microorganisms can act as a non-toxic and natural reagent for fast and eco-friendly biosynthesis of metal nanoparticles and their oxides $[9,18]$

\subsection{Determination of volatile compounds}

The volatile compounds in the Pelargonium hortorum aqueous extract were prepared using the liquid-liquid extraction by n-hexane solution through SS-DLPME method. The number of volatile components of the organic extract was identified by the GC/MS method. The constituents were identified by comparing their MS spectra with certified reference compounds, and were confirmed by comparison of their retention indices with those of certified reference compounds [35-37]. 17 out of 22 components were detected in the organic extract, which formed about $93.5 \%$ of the total extract (Table 1). The major compounds were $\alpha$-pinene (19.46\%), $\alpha$-fenchyl acetate (16.57\%), limonene (11.45\%), trans- $\beta$-caryophyllene $(11.28 \%)$ and camphene $(8.38 \%)$. The analysis of the volatile compounds showed that the identified chemical compounds were much similar to the volatile compounds detected from the specie 
grown wildly in the west of Iran [37].

\section{"Table 1"}

\subsection{Biosynthesized $\mathrm{CeO}_{2}$-NPs characterization}

$\mathrm{UV}-\mathrm{Visible}$ spectroscopy technique was used for monitoring the formation of $\mathrm{CeO}_{2}-\mathrm{NPs}$. In this technique, successful biosynthesis of $\mathrm{CeO}_{2}-\mathrm{NPs}$ was confirmed with respect to the color change of the cerium salt solution from light yellow to whitish-brown after the addition of the drops of the plant extract [32]. In addition, creation of a strong absorption spectra at a maximum wavelength of $325 \mathrm{~nm}$ due to surface plasmon resulting to the charge transfer from $\mathrm{O}_{2} \mathrm{P}$ to $\mathrm{Ce}_{4 \mathrm{f}}$ orbitals was another sign of the production of $\mathrm{CeO}_{2}-\mathrm{NPs}$ (Fig 1), which is highly consistent with the reported results $[6,31,32]$. Also, the optimization of the conditions for the production of the largest amount of $\mathrm{CeO}_{2}-\mathrm{NPs}$ with dimensions less than $50 \mathrm{~nm}$ was performed by measuring the intensity of the absorption spectra and displacement at the maximum wavelength position by a UV-Vis spectrophotometer. The conditions that lead to recording the highest absorption and displacement spectra of blue shift due to the production of more nanoparticles and their smaller size, respectively, were selected as the optimal conditions. Accordingly, 80 $\mathrm{mL}$ of cerium salt of $0.1 \mathrm{M}, 20 \mathrm{~mL}$ of the extract, temperature $80{ }^{\circ} \mathrm{C}$, and time of $2 \mathrm{~h}$ were selected as the optimal conditions for biosynthesis of $\mathrm{CeO}_{2}-\mathrm{NPs}$. Furthermore, the direct optical band gap energy as a property in the biosynthesized $\mathrm{CeO}_{2}-\mathrm{NPs}$ was estimated as $3.81 \mathrm{eV}$ by the Tauc equation $(E g=1239.8 / \lambda)[38]$, where $E g$ and $\lambda$ are the band gap energy $(\mathrm{eV})$ and wavelength (nm) of the absorption edge in the UV-Vis spectrum, respectively. It should be noted that when the amount of the extract was increased to more than $20 \mathrm{ml}$, the size of the particle produced was larger (it showed a red shift) and the band gap decreased, a trend that has been reported in some previous studies as well [6].

"Fig. 1"

The FT-IR spectroscopy was carried out to identify the functional groups of the biosynthesized $\mathrm{CeO}_{2}$-NPs. Fig. 2 shows the FT-IR spectrum of the biosynthesized $\mathrm{CeO}_{2}-\mathrm{NPs}$ where the broad 
peak was located at $3450 \mathrm{~cm}^{-1}$ of the attributed $\mathrm{O}-\mathrm{H}$ stretching, which might be because of the presence of water. Other strong bands were 1050 and $486 \mathrm{~cm}^{-1}$, which can be attributed to the stretching of the ending vibrations of the O-Ce-O and, Ce-O respectively [39]. The results of this analysis showed that there was no functional group of the extract on the biosynthesized $\mathrm{CeO}_{2}$-NPs due to calcination at $400{ }^{\circ} \mathrm{C}$.

"Fig. 2"

Fig. 3 displays the XRD pattern of the biosynthesized $\mathrm{CeO}_{2}-\mathrm{NPs}$. As shown in this pattern, the peaks that appear at $2 \theta=27.78^{\circ}, 32.20^{\circ}, 46.16^{\circ}, 54.46^{\circ}, 58.55^{\circ}, 69.12^{\circ}$, and $77.56^{\circ}$ are indexed to (111), (200), (220), (311), (222), (400), and (420) facets, respectively. These peaks corresponded to the high purity single phase of $\mathrm{CeO}_{2}-\mathrm{NPs}$ and in a face center of the fluorite cubic structure according to JCPDS No. 34-03942, which is in good agreement with the reported results in the previous studies $[6,40]$. The crystalline size of the biosynthesized $\mathrm{CeO}_{2}$ NPs was calculated using Scherrer's formula $(\mathrm{D}=0.89 \lambda / \beta \cos \theta)[41]$ and was accordingly found to be $29 \mathrm{~nm}$ for the highest peak at $2 \theta=25.22^{\circ}$.

"Fig. 3"

Moreover, a DLS analysis was applied to determine the zeta potential charge (ZPC) and estimate the hydrodynamic particle size distribution of the biosynthesized $\mathrm{CeO}_{2}-\mathrm{NPs}$, as shown in Fig. 4. It was found that the net surface charge of the biosynthesized $\mathrm{CeO}_{2}-\mathrm{NPs}$ was -25.8 $\mathrm{mV}$, which shows its good colloidal stability [6]. Also, the DLS histogram (inset in Fig.4) indicates that the biosynthesized $\mathrm{CeO}_{2}-\mathrm{NPs}$ has a narrow pattern with an average hydrodynamic diameter of about $34 \mathrm{~nm}$.

Furthermore, FE-SEM image was used to identify the morphology and estimate the particle size of the biosynthesized $\mathrm{CeO}_{2}-\mathrm{NPs}$ (see Fig. 5). This figure shows a uniform distribution of the biosynthesized $\mathrm{CeO}_{2}-\mathrm{NPs}$ and a spherical shape as well as a mean particle size of $33 \mathrm{~nm}$, which is in good agreement with the estimated results from the XRD and DLS techniques. In addition, the EDX analysis (illustrated in Fig. 5) was used to study the chemical elements in the biosynthesized $\mathrm{CeO}_{2}$-NPs. The EDX results showed the major peaks correspond to the $\mathrm{Ce}$ 
and $\mathrm{O}$ element. Such correspondence was not detected for other elements, which confirms the purity of the biosynthesized $\mathrm{CeO}_{2}$-NPs.

"Figs.4 \& 5"

Also, the specific surface area, pore volume, and pore radius of the biosynthesized $\mathrm{CeO}_{2}-\mathrm{NPs}$ were characterized by $\mathrm{N}_{2}$ adsorption-desorption porosimetry using a BET analyzer. Fig 6 shows the $\mathrm{N}_{2}$ adsorption-desorption isotherm of the biosynthesized $\mathrm{CeO}_{2}-\mathrm{NPs}$. This isotherm exhibits a type IV isotherm with an $\mathrm{H}_{2}$ hysteresis loop in the $\mathrm{p} / \mathrm{p}_{0}$ range of $0.35-0.98$, which indicates formation of a mesoporous host in all the $\mathrm{CeO}_{2}-\mathrm{NP}$ structures [42]. The BET-specific surface areas of the biosynthesized $\mathrm{CeO}_{2}-\mathrm{NPs}$ are $33.84 \mathrm{~m}^{2} / \mathrm{g}$ with mean pore diameters of 9.31 $\mathrm{nm}$ and total pore volume of $0.078 \mathrm{~cm}^{3} / \mathrm{g}$. The inset figure shows the pore size distribution of $\mathrm{CeO}_{2}$-NPs. The main peak was located in the range of about $2.4 \mathrm{~nm}$, which confirms the mesoporous nanoparticles classification [42].

"Fig. 6"

\subsection{Antioxidant activity}

The antioxidant potential of the Pelargonium hortorum extract was evaluated by the scavenging potential of stable methanolic DPPH free radicals (Fig. 7). In the presence of the extract, the color of the DPPH solution changed from deep violet to light yellowish with an increase in the contact time [33]. The percentage of the scavenging of DPPH increased with an increase in the extract amount from 5 to $100 \mu \mathrm{g} / \mathrm{mL}$ and reached about $85.4 \%$ at about 100 $\mu \mathrm{g} / \mathrm{mL}$. The results suggest that the phenolic components (total phenol and flavonoid) contributed significantly to the antioxidant capacity of the extract. The antioxidant activity of the biosynthesized $\mathrm{CeO}_{2}$-NPs was also evaluated using the DPPH method. The maximum antioxidant activities (69.8\%) were exhibited when $100 \mu \mathrm{g} / \mathrm{mL}$ of the $\mathrm{CeO}_{2}-\mathrm{NPs}$ was used. Since $100 \%$ of the free radical could not be scavenged by a certain substance [43], the antioxidant potential was evaluated by the $\mathrm{IC}_{50}$ value (the scavenging concentration needed to scavenge $50 \%$ of the DPPH free radical) of the substance. The results show that the $\mathrm{IC}_{50}$ of 
extract and $\mathrm{CeO}_{2}-\mathrm{NPs}$ were found to be $29.3 \mu \mathrm{g} / \mathrm{mL}$ and $42.7 \mu \mathrm{g} / \mathrm{mL}$, respectively.

"Fig. 7"

\subsection{Photocatalytic activity}

The photocatalytic activity of the biosynthesized $\mathrm{CeO}_{2}-\mathrm{NPs}$ was studied by determining the reduction of $1.5 \mathrm{~L}$ of $\mathrm{Cr}(\mathrm{VI})$ ions in an aqueous solution $(10 \mathrm{mg} / \mathrm{L})$ with a natural $\mathrm{pH}$ of 5.5 under irradiation with UV light using $200 \mathrm{mg} / \mathrm{L} \mathrm{CeO}_{2}-\mathrm{NPs}$ as the photocatalyst. About $94 \%$ $\mathrm{Cr}(\mathrm{VI})$ ions reduction was achieved after $60 \mathrm{~min}$ treatments. The photocatalytic reaction mechanism of the biosynthesized $\mathrm{CeO}_{2}-\mathrm{NPs}$ is suggested when $\mathrm{CeO}_{2}-\mathrm{NPs}$ are excited by light, as a result of which the electrons $\left(\mathrm{e}^{-}\right)$from the valence band move to the conduction band leaving a hole $\left(\mathrm{h}^{+}\right)$in the valance band [6]. The formation of the electrons in the conduction band plays a role in the reduction of the $\mathrm{Cr}(\mathrm{VI})$ ions. The reaction mechanism in equations (36) is a follows:

$$
\begin{aligned}
& \mathrm{CeO}_{2}+h v \rightarrow \mathrm{CeO}_{2}\left(e^{-}+h^{+}\right) \\
& 3 \mathrm{CeO}_{2}\left(e^{-}+h^{+}\right)+3 \mathrm{Cr}(\mathrm{VI}) \rightarrow \mathrm{Cr}(\mathrm{III})+3 \mathrm{CeO}_{2}\left(h^{+}\right) \\
& 3 \mathrm{CeO}_{2}\left(h^{+}\right)+3 \mathrm{H}_{2} \mathrm{O} \rightarrow 6 \mathrm{HO}^{\bullet}+3 \mathrm{CeO}_{2} \\
& 6 \mathrm{HO}^{\bullet} \rightarrow 3 \mathrm{H}_{2} \mathrm{O}_{2}
\end{aligned}
$$

which, in acidic media indirectly was generated $\mathrm{H}_{2} \mathrm{O}_{2}$ molecules leads to rapid reduction of $\mathrm{Cr}(\mathrm{VI})$ ions [44]. In this section, the kinetic reduction of the $\mathrm{Cr}(\mathrm{VI})$ ions was also investigated and analyzed by $-\ln \frac{C_{0}}{C_{t}}=k t$ equation. From the slope of $\ln \frac{C_{0}}{C_{t}}$ plot versus time (Fig. 8), the rate constant $(k)$ was obtained as $0.0791 / \mathrm{min}$ and the coefficient $\left(R^{2}\right)$ was also determined as 0.981 for the process. The rate of the $\mathrm{Cr}(\mathrm{VI})$ ions reduction in this process was fitted to the pseudo-first-order kinetic model. Finally, the stability of the biosynthesized $\mathrm{CeO}_{2}-\mathrm{NPs}$ was evaluated after its regeneration. Briefly, the used $\mathrm{CeO}_{2}-\mathrm{NPs}$ was washed with hydrochloric acid $0.1 \mathrm{M}$ and then sonicated in boiling double distillate water for $15 \mathrm{~min}$, and then dried in oven 
at $80{ }^{\circ} \mathrm{C}$ for $2 \mathrm{~h}$. The results revealed (Fig. 8) that the $\mathrm{Cr}(\mathrm{VI})$ reduction efficiency after a six time treatment process was reduced about $6 \%$.

"Fig. 8"

\section{Conclusions}

In this work, the phytochemical composition in the aqueous extract of Pelargonium hortorum from Iran, was studied. The amounts of the total phenolic and flavonoid contents in the extract were found to be $136.5 \mathrm{mg} \mathrm{GA} / \mathrm{g}$ and $63.9 \mathrm{mg} \mathrm{RU} / \mathrm{g}$, respectively. Seventeen compounds (about $93.5 \%$ ) of the total volatile constituents were identified. $\alpha$-pinene (25.28\%) and fenchyl acetate $(20.63 \%)$ were the main components of the volatile constituent. The aqueous extract of Pelargonium hortorum was used to eco-friendly biosynthesis of $\mathrm{CeO}_{2}-\mathrm{NPs}$. Different techniques were used for the characterization of biosynthesized $\mathrm{CeO}_{2}-\mathrm{NPs}$. The prepared $\mathrm{CeO}_{2}$ NPs were spherical in shape, with an average size of $28 \mathrm{~nm}$. The synthesized $\mathrm{CeO}_{2}-\mathrm{NPs}$ had $33.84 \mathrm{~m}^{2} / \mathrm{g}$ BET surface area, $9.31 \mathrm{~nm}$ mane diameter pore, and a total pore volume of 0.078 $\mathrm{cm}^{3} / \mathrm{g}$. The $\mathrm{IC}_{50}$ value of $42.7 \mu \mathrm{g} / \mathrm{mL}$ was determined for biosynthesized $\mathrm{CeO}_{2}-\mathrm{NPs}_{\text {s }}$ The reduction efficiency of $94 \%$ in an aqueous solution containing $10 \mathrm{mg} / \mathrm{L}$ of $\mathrm{Cr}(\mathrm{VI})$ with $\mathrm{pH}$ of 5.5 by using $200 \mathrm{mg} / \mathrm{L} \mathrm{CeO}_{2}-\mathrm{NPs}$ during $60 \mathrm{~min}$ was achieved. The rate of the $\mathrm{Cr}(\mathrm{VI})$ ions reduction process was fitted to the pseudo-first-order kinetic model with a rate constant of 0.079 $1 / \mathrm{min}$.

\section{Acknowledgement}

The authors wish to acknowledge the university authorities for providing the financial support to carry out this work.

\section{Disclosure statement}

There is no conflict of interest on this research. 


\section{References}

[1] Nadeem M., Khan R., Afridi K., Nadhman A., Ullah S., Faisal S., Mabood Z. U., Hano C., Abbasi B. H., Green synthesis of cerium oxide nanoparticles $\left(\mathrm{CeO}_{2} \mathrm{NPs}\right)$ and their antimicrobial applications: A Review, International Journal of Nanomedicine, 2020, 15:59515961.

[2] Das S., Dowding J. M., Klump K. E., McGinnis J. F., Self W. T., Seal S., Cerium oxide nanoparticles: applications and prospects in nanomedicine, Nanomedicine, 2013, 8(9):14831508 .

[3] Walkey C., Das S., Seal S., Erlichman J., Heckman K., Ghibelli L., Traversa E., McGinnis J. F., Self W. T., Catalytic properties and biomedical applications of cerium oxide nanoparticles, Environmental Science: Nano, 2015, 2(1):33-53.

[4] Rajeshkumar S., Naik P., Synthesis and biomedical applications of cerium oxide nanoparticles-a review, Biotechnology Reports, 2018, 17:1-5.

[5] Magudieshwaran R., Ishii J., Raja K. C. N., Terashima C., Venkatachalam R., Fujishima A., Pitchaimuthu S., Green and chemical synthesized $\mathrm{CeO}_{2}$ nanoparticles for photocatalytic indoor air pollutant degradation, Materials Letters, 2019, 239:40-44.

[6] Elahi B., Mirzaee M., Darroudi M., Kazemi Oskuee R., Sadri K., Amiri M. S., Preparation of cerium oxide nanoparticles in salvia macrosiphon boiss seeds extract and investigation of their Photo-catalytic activities, Ceramics International, 2018, 45:4790-4797.

[7] Arunachalam T, Karpagasundaram M, Rajarathinam N. Ultrasound assisted green synthesis of cerium oxide nanoparticles using prosopis juliflora leaf extract and their structural, optical and antibacterial properties, Materials Science-Poland, 2017, 35(4):791-798.

[8] Singh K. R. B., Nayak V., Sarkar T., Singh R. P., Cerium oxide nanoparticles: properties, biosynthesis and biomedical application, RSC Advances, 2020, 10(45):27194-27214.

[9] Ebrahiminezhad A., Zare-Hoseinabadi A., Sarmah A. K., Taghizadeh S., Ghasemi Y., Berenjian A., Plant-mediated synthesis and applications of iron nanoparticles, Molecular Biotechnology, 2018, 60:154-168.

[10] Maqbool Q., Nazar M., Naz S., Hussain T., Jabeen N., Kausar R., Anwaar S., Abbas F., Jan T., Antimicrobial potential of green synthesized $\mathrm{CeO}_{2}$ nanoparticles from olea europaea leaf extract, International Journal of Nanomedicine, 2016, 11:5015-5025.

[11] Miri A, Darroudi M, Sarani M. Biosynthesis of cerium oxide nanoparticles and its cytotoxicity survey against colon cancer cell line, Applied Organometallic Chemistry, 2020, 24(1):e5308.

[12] Xiao Y., Tan S., Wang D., Wua J., Jia T., Liu Q., Qi Y., Qi X., He P., Zhou M., $\mathrm{CeO}_{2} / \mathrm{BiOIO}_{3}$ heterojunction with oxygen vacancies and $\mathrm{Ce}^{4+} / \mathrm{Ce}^{3+}$ redox centers 
synergistically enhanced photocatalytic removal heavy metal, Applied Surface Science, 2020, 530:147116.

[13] Balakumar V., Kim H., Manivannan R., Kim H., Ryu J. W., Heo G., Son Y. A., Ultrasound-assisted method to improve the structure of $\mathrm{CeO}_{2} @$ polyprrole core-shell nanosphere and its photocatalytic reduction of hazardous $\mathrm{Cr}^{6+}$, Ultrasonics Sonochemistry, 2019, 59:104738.

[14] Kashinath L., Namratha K., Byrappa K., Microwave mediated synthesis and characterization of $\mathrm{CeO}_{2}-\mathrm{GO}$ hybrid composite for removal of chromium ions and its antibacterial efficiency, Journal of Environmental Sciences, 2019, 76:65-79.

[15] Saravanakumar K., Karthik R., Chen S. M., Vinoth Kumar J., Prakash K., Muthuraj V., Construction of novel $\mathrm{Pd} / \mathrm{CeO}_{2} / \mathrm{g}-\mathrm{C}_{3} \mathrm{~N}_{4}$ nanocomposites as efficient visible-light photocatalysts for hexavalent chromium detoxification, Journal of colloid and Interface Science, 2017, 504:514-526.

[16] Priyadharsan A., Vasanthakumar V., Karthikeyan S., Raj V., Shanavas S., Anbarasan P. M., Multi-functional properties of ternary $\mathrm{CeO}_{2} / \mathrm{SnO}_{2} / \mathrm{rGO}$ nanocomposites: Visible light driven photocatalyst and heavy metal removal Author links open overlay panel, Journal of Photochemistry and Photobiology A: Chemistry, 2017, 346:32-45.

[17] Boukhris M., Simmonds M. S., Sayadi S., Bouaziz M., Chemical composition and biological activities of polar extracts and essential oil of rose-scented geranium, Pelargonium graveolens, Phytotherapy Research, 2013, 27(8):1206-1213.

[18] Mohammadlou M., Jafarizadeh-Malmiri H., Maghsoudi H., Hydrothermal green synthesis of silver nanoparticles using Pelargonium/Geranium leaf extract and evaluation of their antifungal activity, Green Processing and Synthesis, 2017, 6:31-42.

[19] Rivera-Rangel R. D., González-Muñoz M. P., Avila-Rodriguez M., Razo-Lazcano T. A., Solans C., Green synthesis of silver nanoparticles in oil-in-water microemulsion and nanoemulsion using geranium leaf aqueous extract as a reducing agent, Colloids and Surfaces A: Physicochemical and Engineering Aspects, 2018, 536:60-67.

[20] Jafarizad A., Safaee K., Gharibian S., Omidi Y., Ekinci D., Biosynthesis and in-vitro study of gold nanoparticles using Mentha and Pelargonium extracts, Procedia Materials Science, 2015, 11:224-230.

[21] Mirończyk A., Timoszyk A., Koziol J. J., Green synthesis and characterization of gold nanoparticles using Pelargonium zonale extract, Jökull Journal, 2015, 65:300-309.

[22] Franco-Romano M., Gil M. L. A., Palacios-Santander J. M., Delgado-Jaén J. J., NaranjoRodríguez I., Hidalgo-Hidalgo De Cisneros J. L., Cubillana-Aguilera L. M., Sonosynthesis of gold nanoparticles from a geranium leaf extract, Ultrasonics Sonochemistry, 2014, 21:15701577. 
[23] Zhang Y. C., Yang M., Zhang G., Dionysiou D. D., $\mathrm{HNO}_{3}$-involved one-step low temperature solvothermal synthesis of $\mathrm{N}$-doped $\mathrm{TiO}_{2}$ nanocrystals for efficient photocatalytic reduction of $\mathrm{Cr}(\mathrm{VI})$ in water, Applied Catalysis B: Environmental, 2013, 142-143:249-258.

[24] Norouzi Esfahani R., Khaghani Sh., Azizi A., Mortazaeinezhad F., Gomarian M., Facile and eco-friendly synthesis of $\mathrm{TiO}_{2} \mathrm{NPs}$ using extracts of Verbascum thapsus plant: an efficient photocatalyst for reduction of $\mathrm{Cr}(\mathrm{VI})$ ions in the aqueous solution, Journal of the Iranian Chemical Society, 2020, 17:205-213.

[25] WHO, Guidelines for Drinking Water Quality (World Health Organization, Geneva, 2006).

[26] Shirzad Siboni M., Samadi M. T., Yang J. K., Lee S. M., Photocatalytic removal of Cr(VI) and $\mathrm{Ni}(\mathrm{II})$ by UV/TiO 2 : kinetic study, Desalination Water Treat, 2012, 40:77-83.

[27] Chen D., Ray A. K., Removal of toxic metal ions from wastewaters by semiconductor photocatalysis, Chemical Engineering Science, 2001, 56:1561-1570.

[28] Shaver L. A., Leung S. H., Puderbaugh A., Angel S. A., Two methods of determining total phenolic content of foods and juices in a general, organic, and biological (GOB) chemistry lab, Journal of Chemical Education, 2011, 88:492-495.

[29] Singleton V. L., Orthofer R., Lamuela-Raventós R. M., Analysis of total phenols and other oxidation substrates and antioxidants by means of Folin-Ciocalteu reagent, Methods in Enzymology, 1999, 299:152-178.

[30] Koosha E., Ramezani M., Niazi Ali, Syringe-to-syringe-dispersive liquid-phase microextraction combined with flame atomic absorption spectrometry for pre-concentration and determination of cobalt with the aid of experimental design, International Journal of Environmental Analytical Chemistry, 2018, 98(6):506-519.

[31] Mansingh S., Kandi D., Kumar Das K., Parida K., A mechanistic approach on oxygen vacancy-engineered $\mathrm{CeO}_{2}$ nanosheets concocts over an oyster shell manifesting robust photocatalytic activity toward water oxidation, ACS Omega, 2020, 5(17):9789-9805.

[32] Muthuvel A., Jothibas M., Mohana V., Manoharan C., Green synthesis of cerium oxide nanoparticles using Calotropis procera flower extract and their photocatalytic degradation and antibacterial activity, Inorganic Chemistry Communications, 2020, 119:108086.

[33] Hung D., Ou, B., Prior, R. L., The chemistry behind antioxidant capacity assays, Journal of Agricultural and Food Chemistry, 2005, 53:1841-1856.

[34] Clesceri L. S., Greenberg A. E., Eaton A. D., Standard methods for the examination of water and wastewater (American Public Health Association, Washington, 1998).

[35] Adams R. P., Identification of essential oil components by gas chromatography/mass spectroscopy, (Allured Publishing Corporation, Illinois, 1995).

[36] Aldermaston, Eight pick index of mass spectra, 2nd Edn, Mass spectroscopy data center, reading, UK 1974. 
[37] Taherpour A., Maroofi H., Kheradmand K., Chemical composition of the essential oil of Pelargonium quercetorum Agnew. of Iran, Natural Product Research, 2007, 21(1):24-27.

[38] Tauc J. C., The optical properties of solids (North Holland, Amsterdam, 1972).

[39] Sreekanth T. V. M., Dillip G. R., Lee Y. R, Picrasma quassioides mediated cerium oxide nanostructures and their post-annealing treatment on the microstructural, morphological and enhanced catalytic performance, Ceramics International, 2016, 42(6):6610-6618.

[40] Maqbool Q., Green-synthesised cerium oxide nanostructures $\left(\mathrm{CeO}_{2}-\mathrm{NS}\right)$ show excellent biocompatibility for phyto-cultures as compared to silver nanostructures (Ag-NS), RSC Advance, 2017, 7:56575-56585.

[41] Hargreaves J. S. J., Some considerations related to the use of the Scherrer equation in powder X-ray diffraction as applied to heterogeneous catalysts, Catalysis, Structure \& Reactivity, 2016, 2:33-37.

[42] Sing K. S. W., Williams R. T., Physisorption Hysteresis Loops and the Characterization of Nanoporous Materials, Adsorption Science \& Technology, 2004, 22(10):773-782.

[43] Brand-Williams W., Cuvelier M. E., Berset C., Use of a free radical method to evaluate antioxidant activity, Food Science and Technology, 1995, 28:25-30.

[44] Pettine M., Campanella L., Millero F. J., Reduction of hexavalent chromium by $\mathrm{H}_{2} \mathrm{O}_{2}$ in acidic solutions, Environmental Science and Technology, 2002, 36:901-907. 
Table 1 Chemical compositions of the extract from Pelargonium.

\begin{tabular}{|c|c|c|c|c|}
\hline No. & Components & $\begin{array}{c}\text { Retention } \\
\text { indices }\end{array}$ & $\begin{array}{l}\text { Retention } \\
\text { time (min) }\end{array}$ & Percentage \\
\hline 1 & $\alpha$-Thujene & 922 & 5.37 & 0.58 \\
\hline 2 & $\alpha$-Pinene & 929 & 5.43 & 19.46 \\
\hline 3 & Camphene & 941 & 5.93 & 8.38 \\
\hline 4 & $\beta$-Pinene & 975 & 6.51 & 2.89 \\
\hline 5 & Myrcene & 989 & 6.83 & 2.45 \\
\hline 6 & $\alpha$-Terpinene & 1018 & 7.24 & 0.81 \\
\hline 7 & p-Cymene & 1021 & 7.42 & 1.68 \\
\hline 8 & Limonene & 1027 & 7.67 & 11.45 \\
\hline 9 & $y$-Terpinene & 1055 & 8.74 & 1.01 \\
\hline 10 & $\alpha$-Terpineol & 1085 & 8.91 & 0.68 \\
\hline 11 & Camphor & 1145 & 10.1 & 2.24 \\
\hline 12 & $\alpha$-Fenchyl acetate & 1201 & 12.36 & 16.57 \\
\hline 13 & Thymol & 1282 & 13.98 & 3.63 \\
\hline 14 & Bornyl acetate & 1288 & 14.27 & 1.95 \\
\hline 15 & Trans- $\beta$-Caryophyllene & 1315 & 14.75 & 11.28 \\
\hline 16 & Germacrene-D & 1355 & 15.76 & 3.54 \\
\hline 17 & $\delta$-Cadinene & 1381 & 16.21 & 4.95 \\
\hline 18 & Unknown & 1427 & 17.56 & 1.62 \\
\hline 19 & Unknown & 1452 & 17.63 & 1.44 \\
\hline 20 & Unknown & 1508 & 17.84 & 0.89 \\
\hline 21 & Unknown & 1582 & 17.95 & 1.64 \\
\hline 22 & Unknown & 1591 & 18.12 & 0.86 \\
\hline
\end{tabular}




\section{Figure captions}

Fig. 1 The UV-Vis spectrum of the biosynthesized $\mathrm{CeO}_{2}-\mathrm{NPs}$

Fig. 2 The FT-IR spectrum of the biosynthesized $\mathrm{CeO}_{2}-\mathrm{NPs}$

Fig. 3 XRD patterns of the biosynthesized of $\mathrm{CeO}_{2}-\mathrm{NPs}$

Fig. 4 Zeta potential charge (ZPC) and the hydrodynamic particle size distribution (inset figure) of the biosynthesized $\mathrm{CeO}_{2}-\mathrm{NPs}$

Fig. 5 The FE-SEM image and EDX spectrum (inset figure) of biosynthesized of $\mathrm{CeO}_{2}-\mathrm{NPs}$.

Fig. $6 \mathrm{~N}_{2}$ adsorption-desorption isotherm of the biosynthesized $\mathrm{CeO}_{2}-\mathrm{NPs}$. The inset figure is the pore radius distribution of $\mathrm{CeO}_{2}-\mathrm{NPs}$

Fig.7 A comparison the antioxidant potential of the Pelargonium extract and biosynthesized $\mathrm{CeO}_{2}-\mathrm{NPs}$

Fig. 8 The kinetic plot in photocatalytic reduction of $\mathrm{Cr}(\mathrm{VI})$ ions under: $[\mathrm{Cr}(\mathrm{VI})]=10 \mathrm{mg} / \mathrm{L}$, $\left[\mathrm{CeO}_{2}-\mathrm{NPs}\right]=200 \mathrm{mg} / \mathrm{L}, \mathrm{pH}=5.5$ and $t=60 \mathrm{~min}$. The inset figure is the reuse time results of biosynthesized $\mathrm{CeO}_{2}-\mathrm{NPs}$ catalyst 


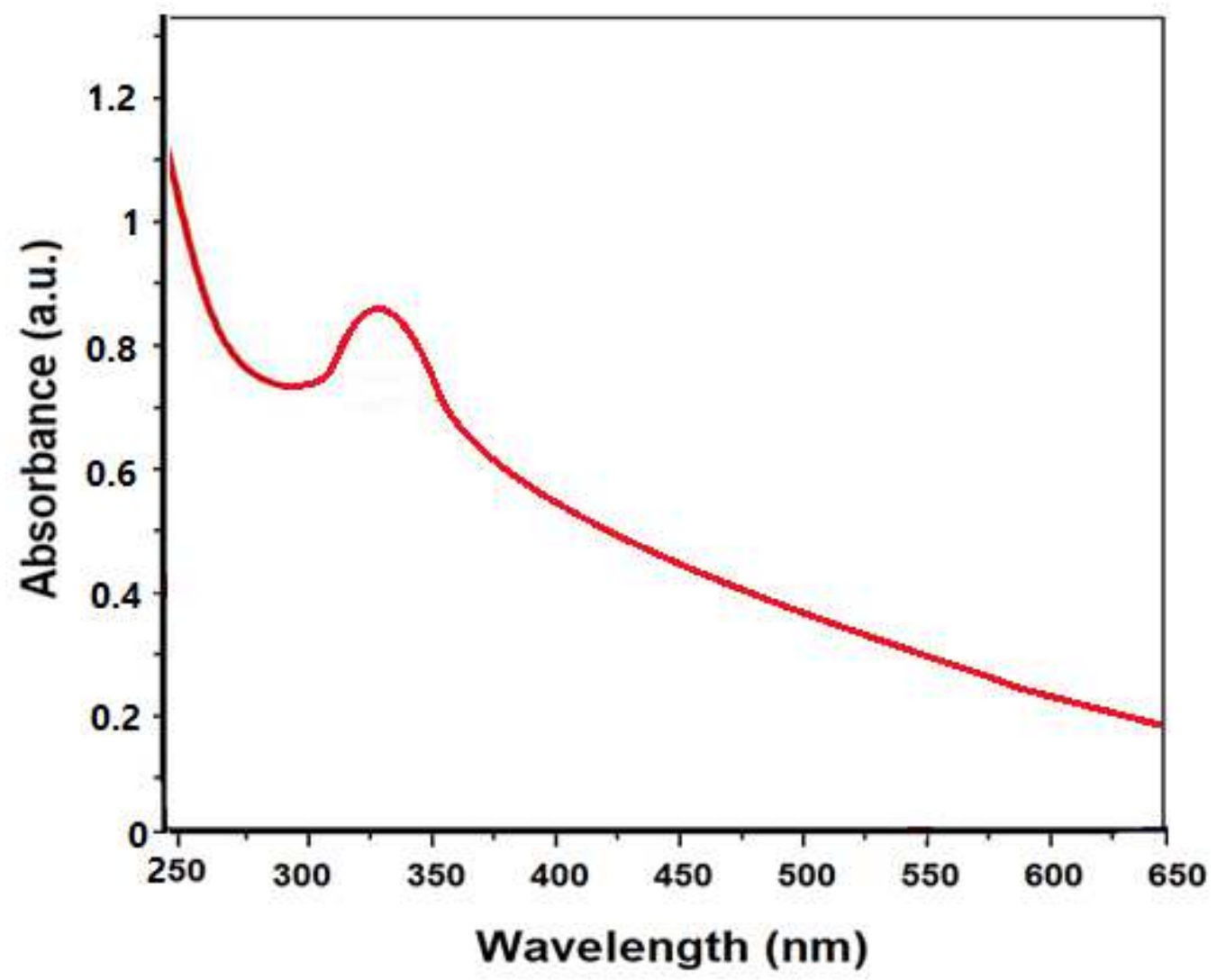

Fig. 1 


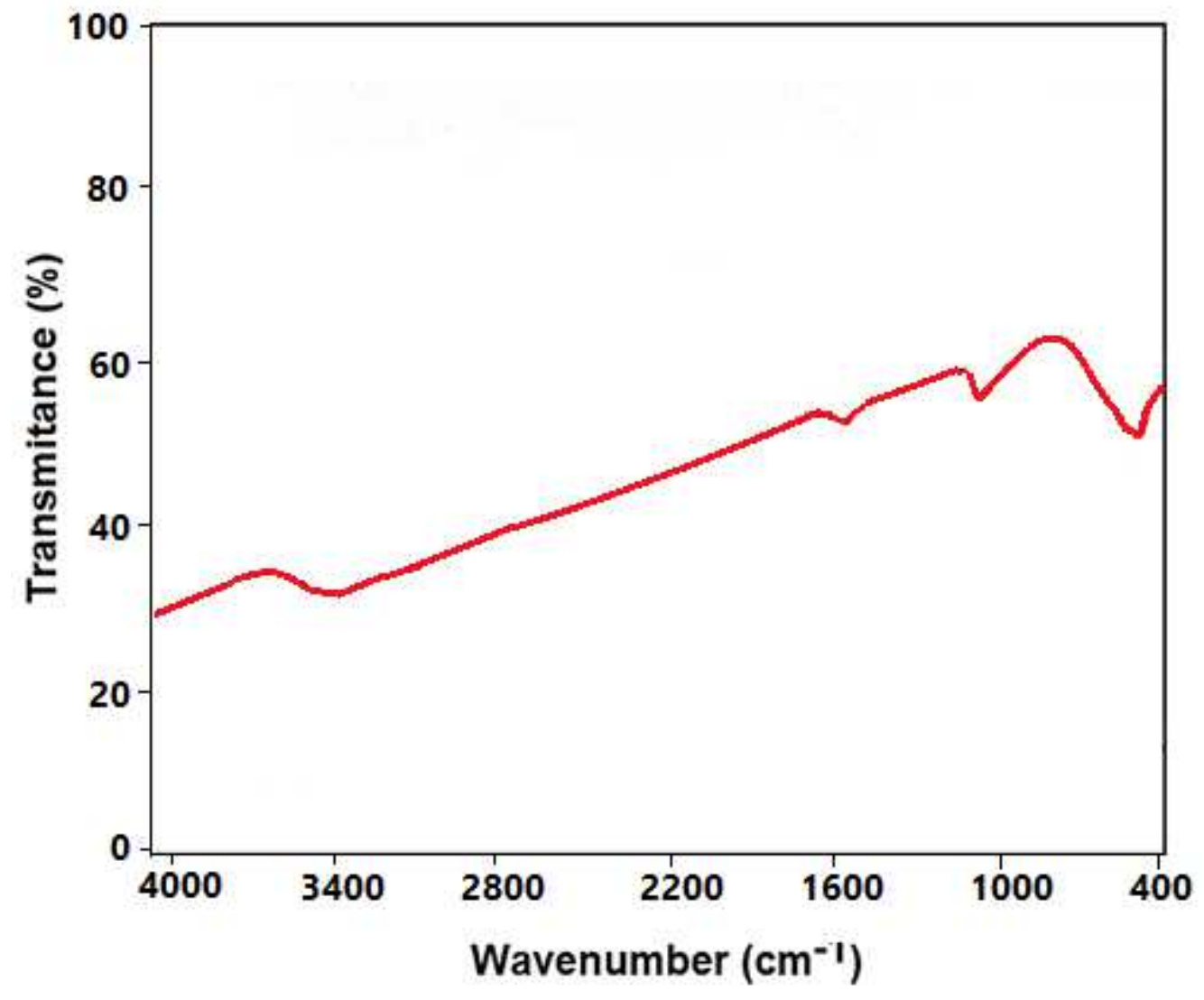

Fig. 2 


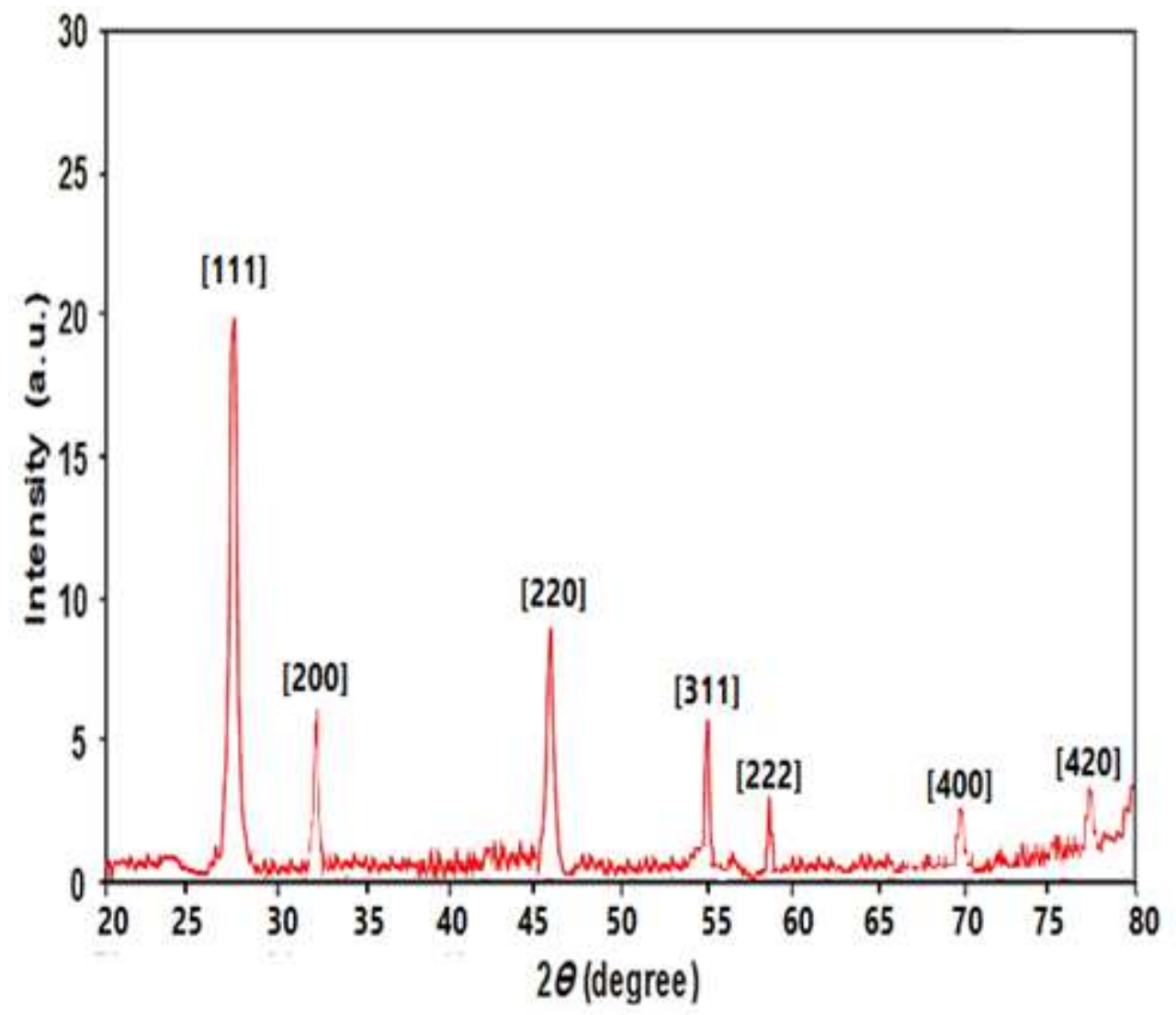

Fig. 3 


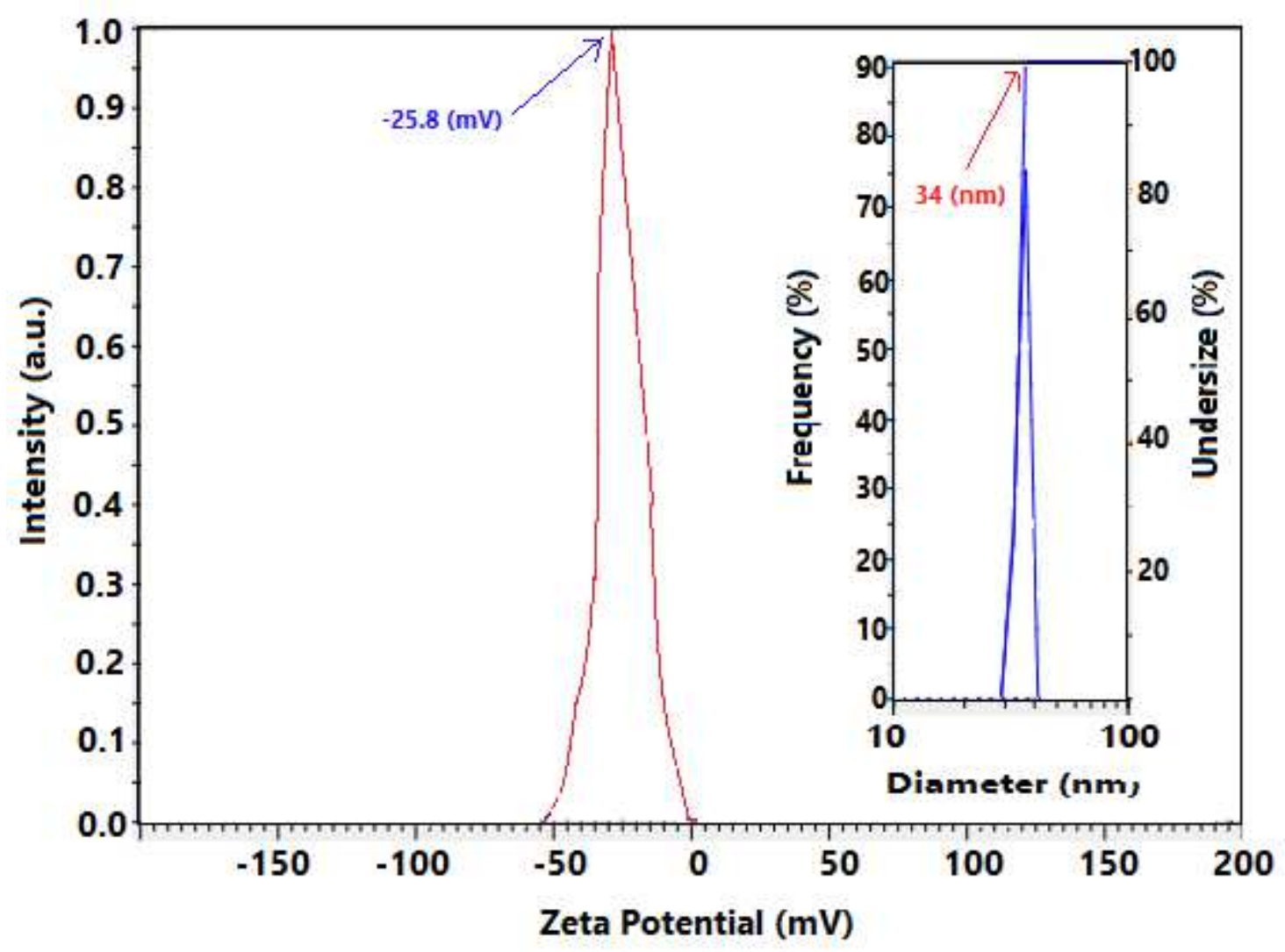

Fig. 4 


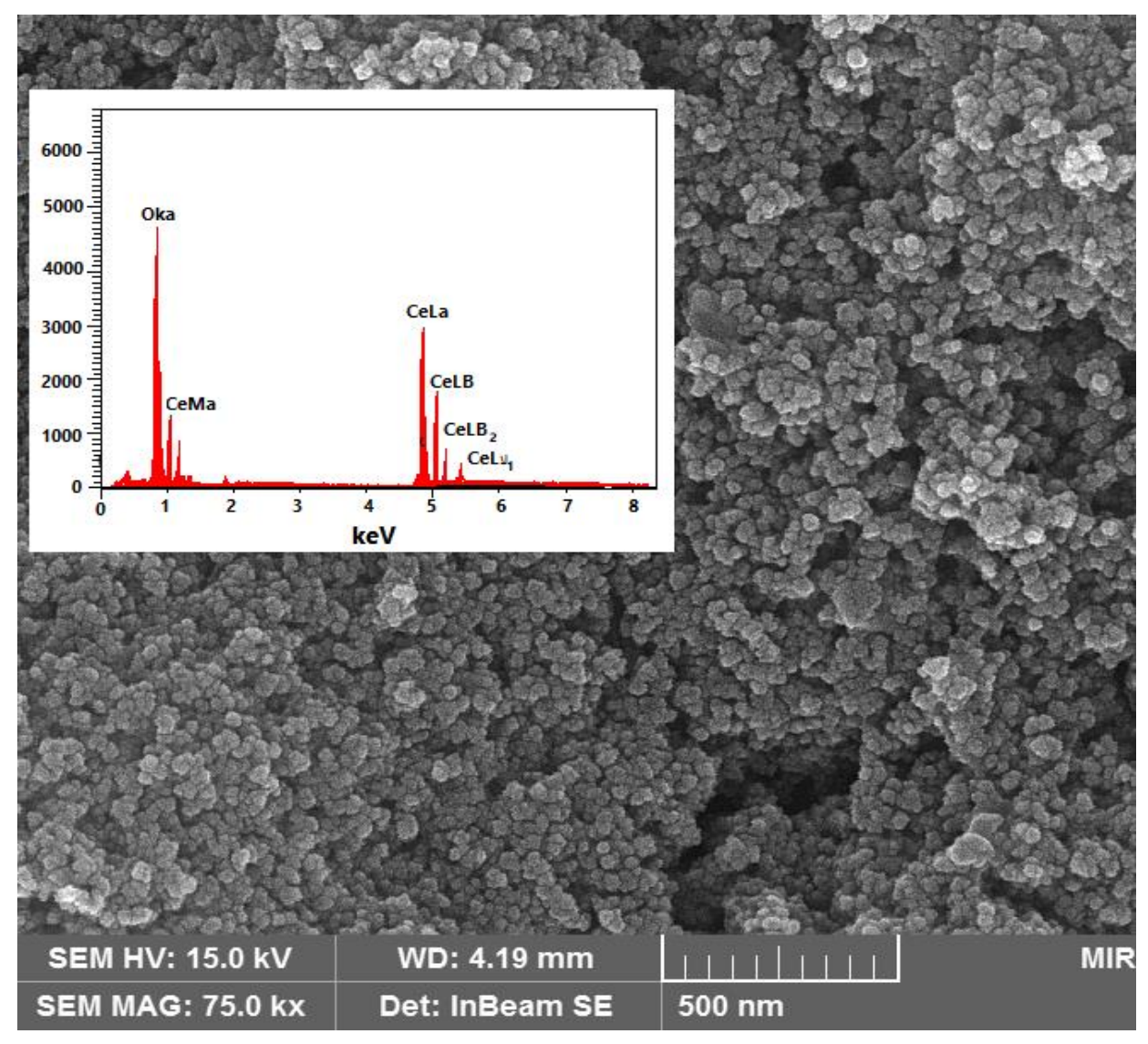

Fig. 5 


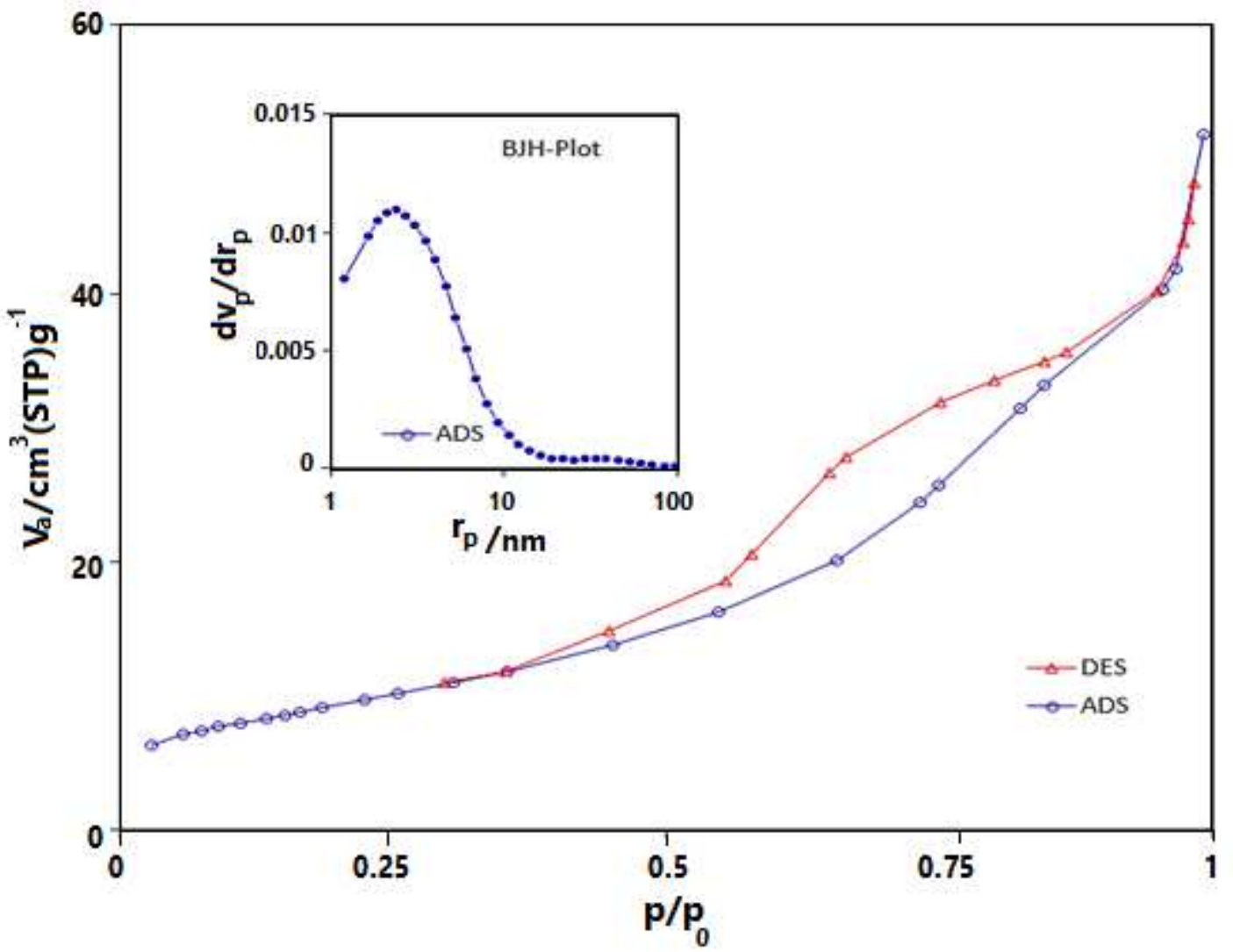

Fig. 6 


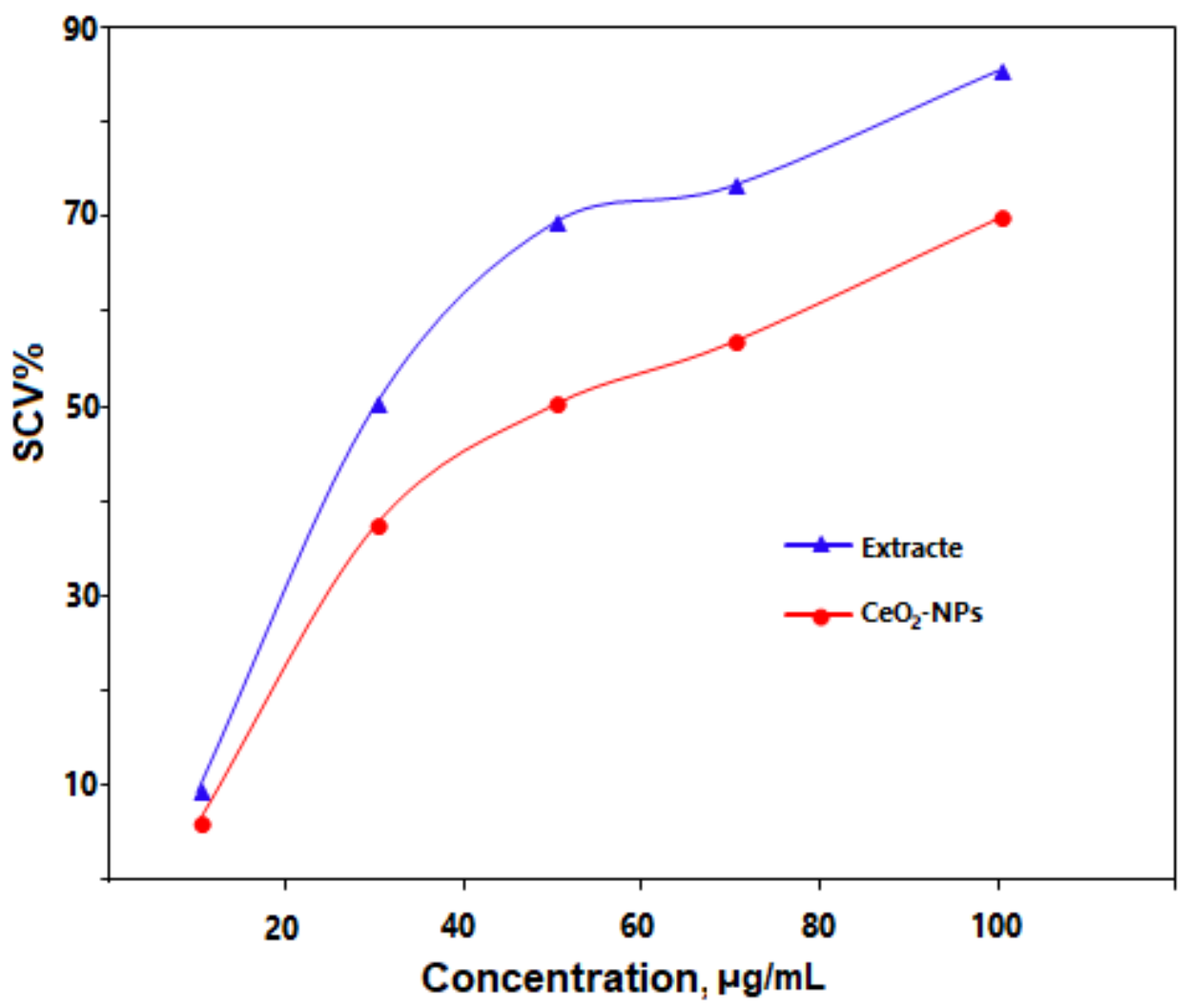

Fig. 7 


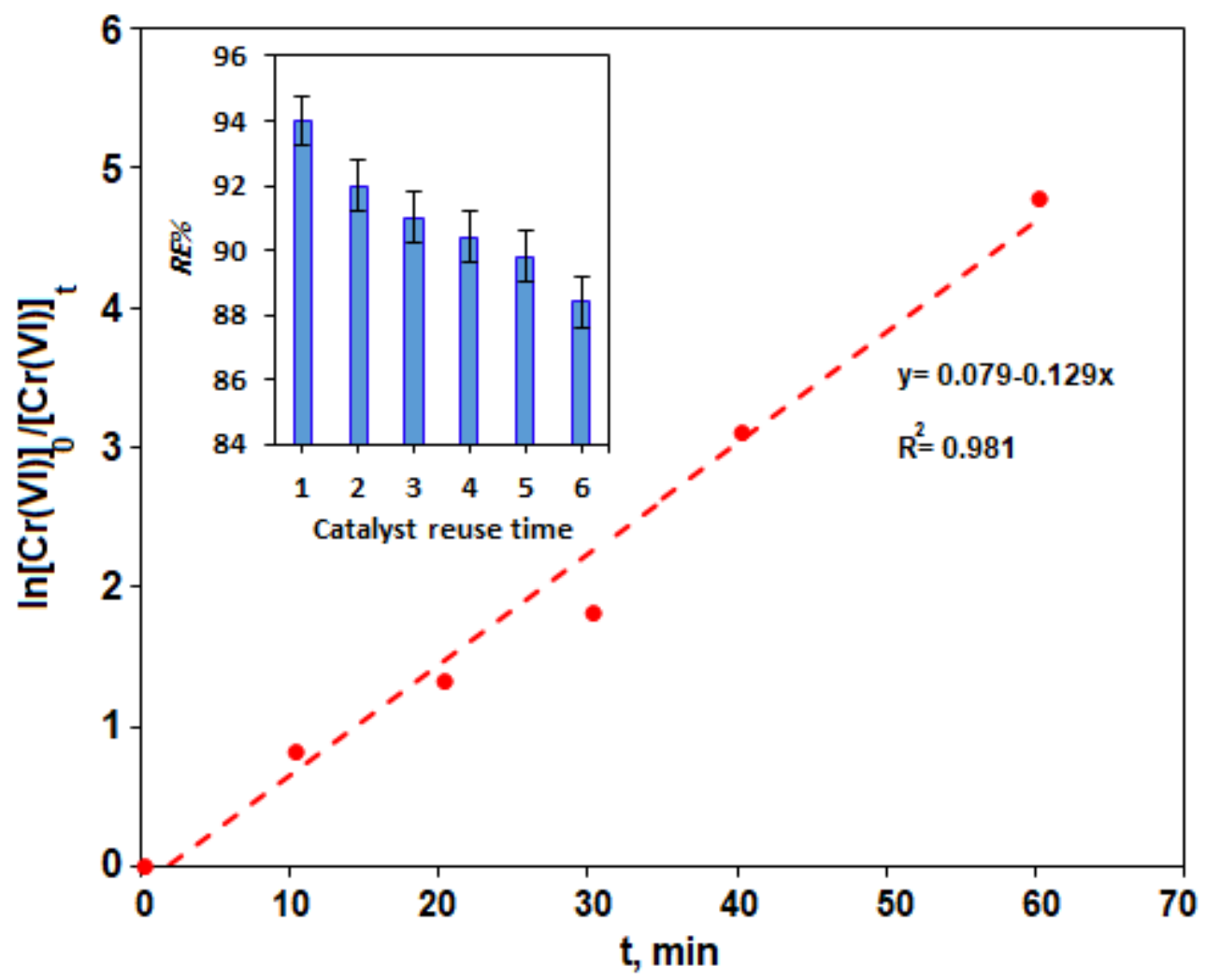

Fig. 8 
Figures

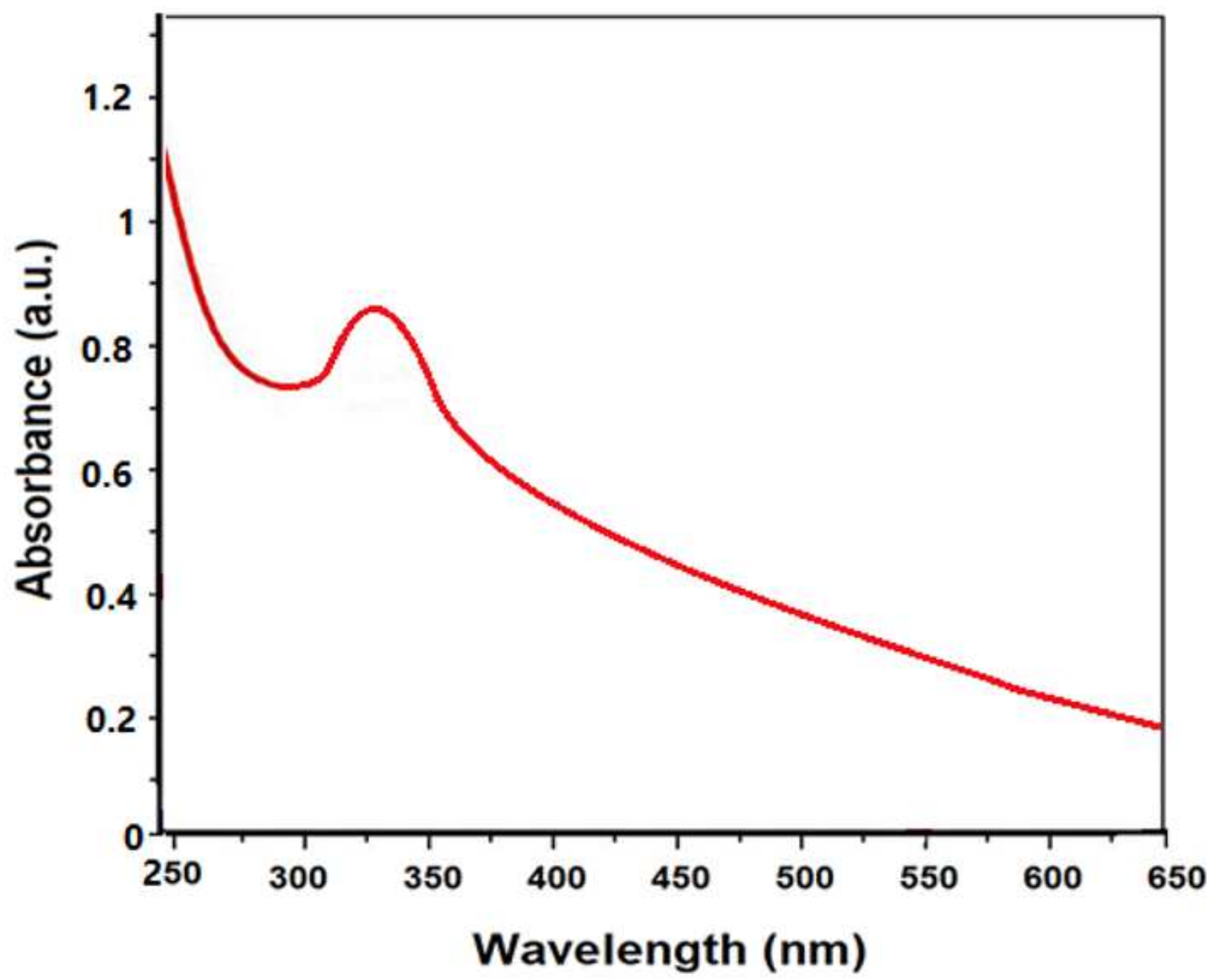

Figure 1

The UV-Vis spectrum of the biosynthesized CeO2-NPs 


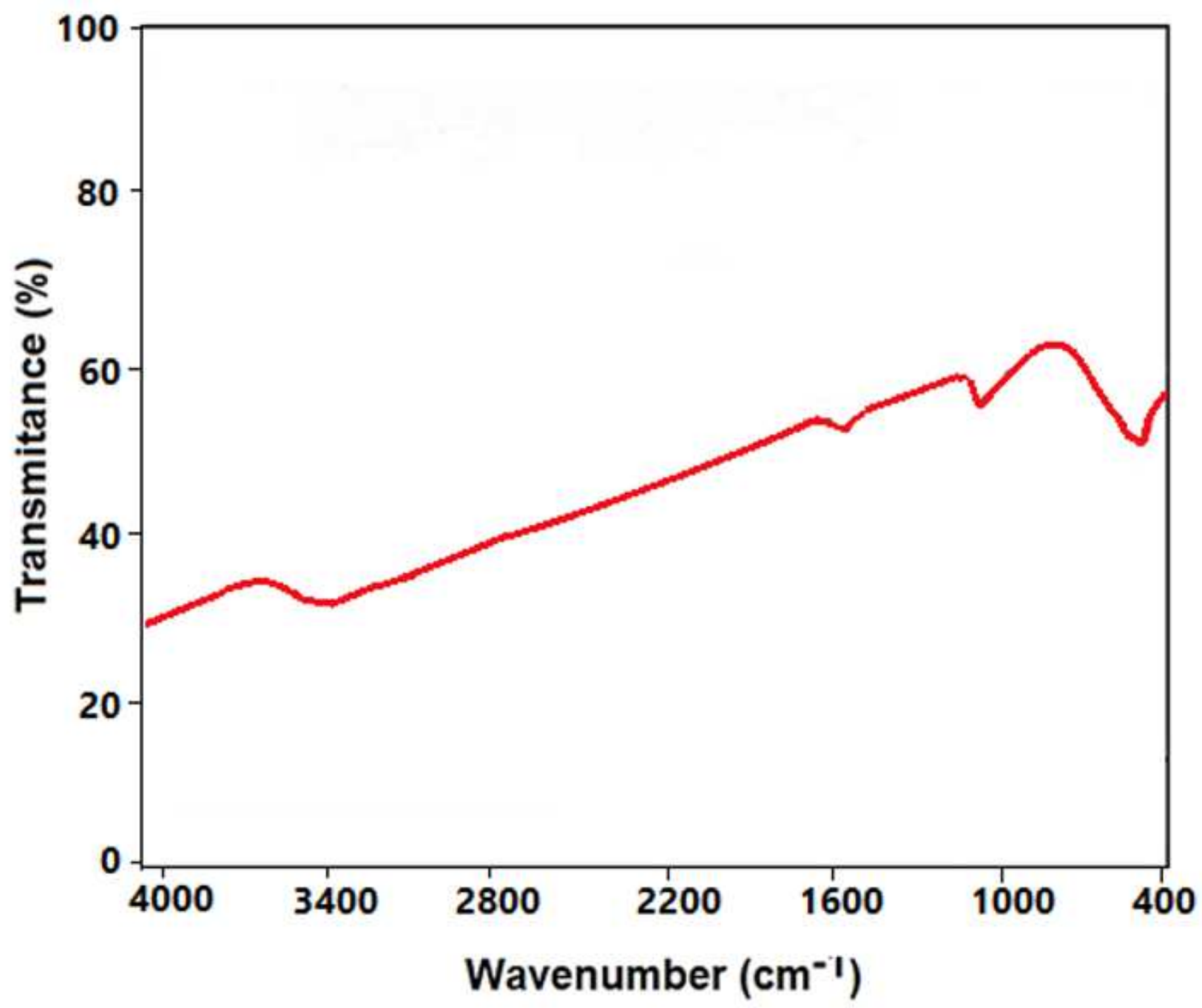

Figure 2

The FT-IR spectrum of the biosynthesized CeO2-NPs 


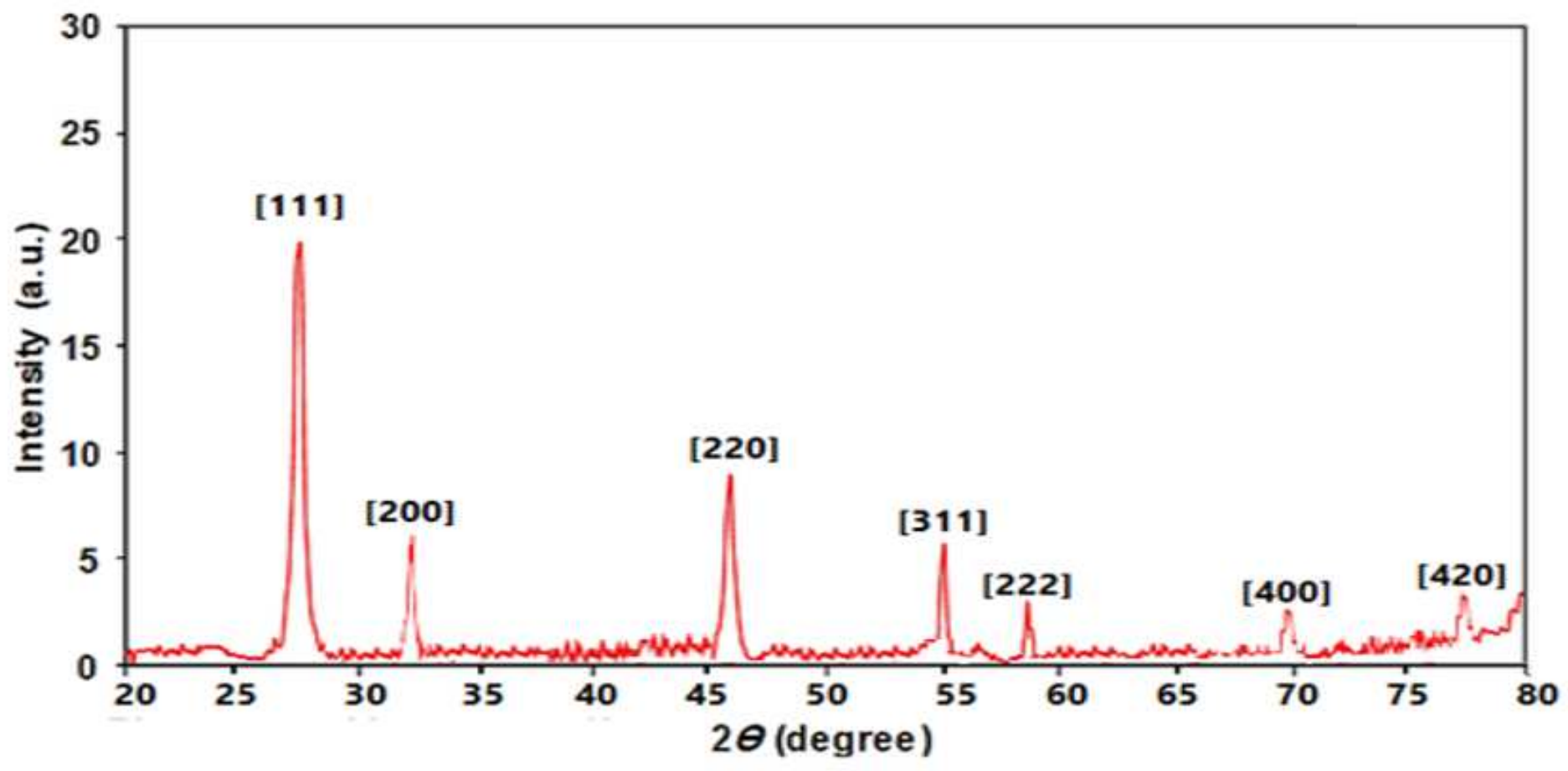

Figure 3

XRD patterns of the biosynthesized of CeO2-NPs 


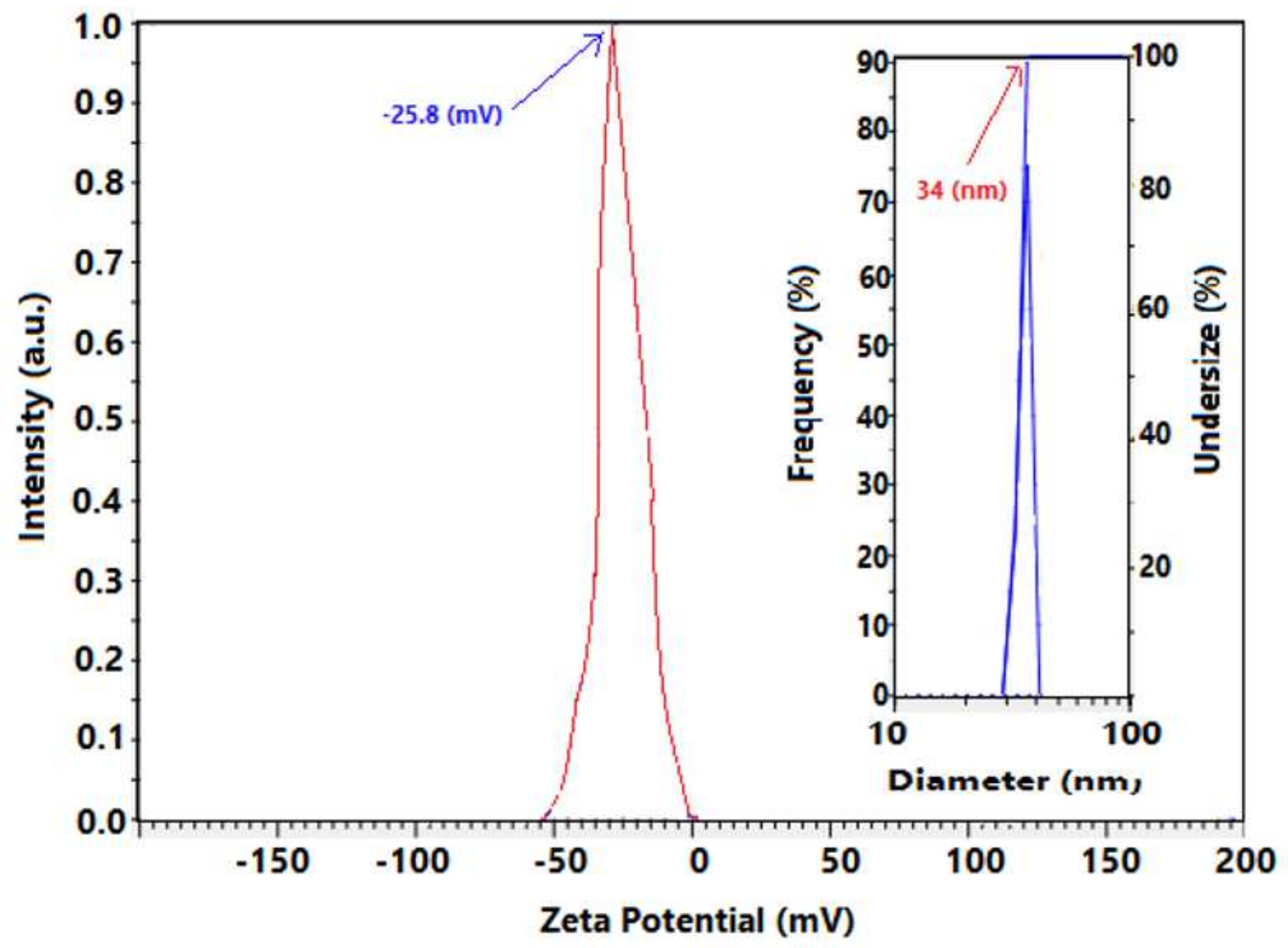

Figure 4

Zeta potential charge (ZPC) and the hydrodynamic particle size distribution (inset figure) of the biosynthesized CeO2-NPs 


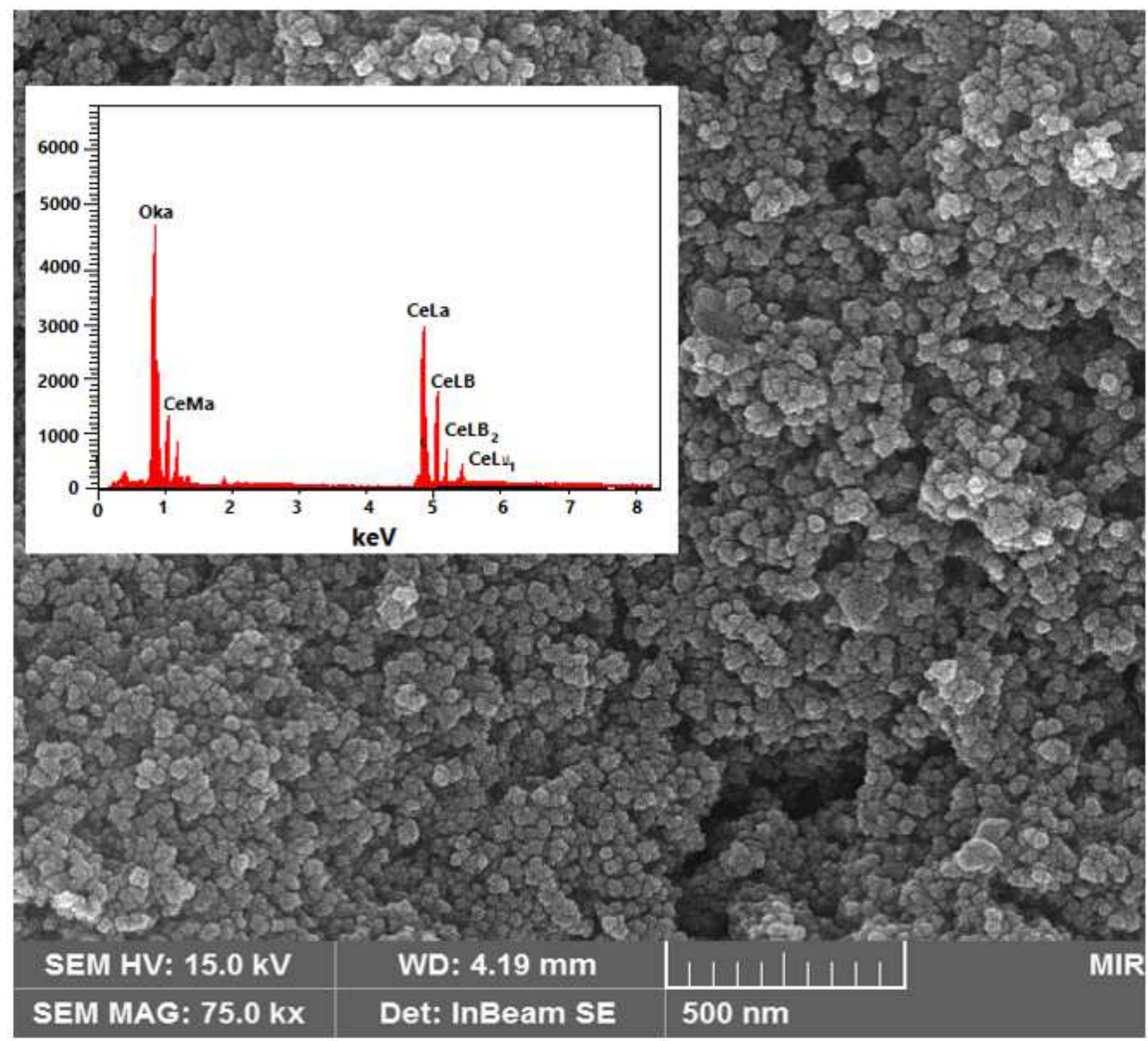

Figure 5

The FE-SEM image and EDX spectrum (inset figure) of biosynthesized of CeO2-NPs. 


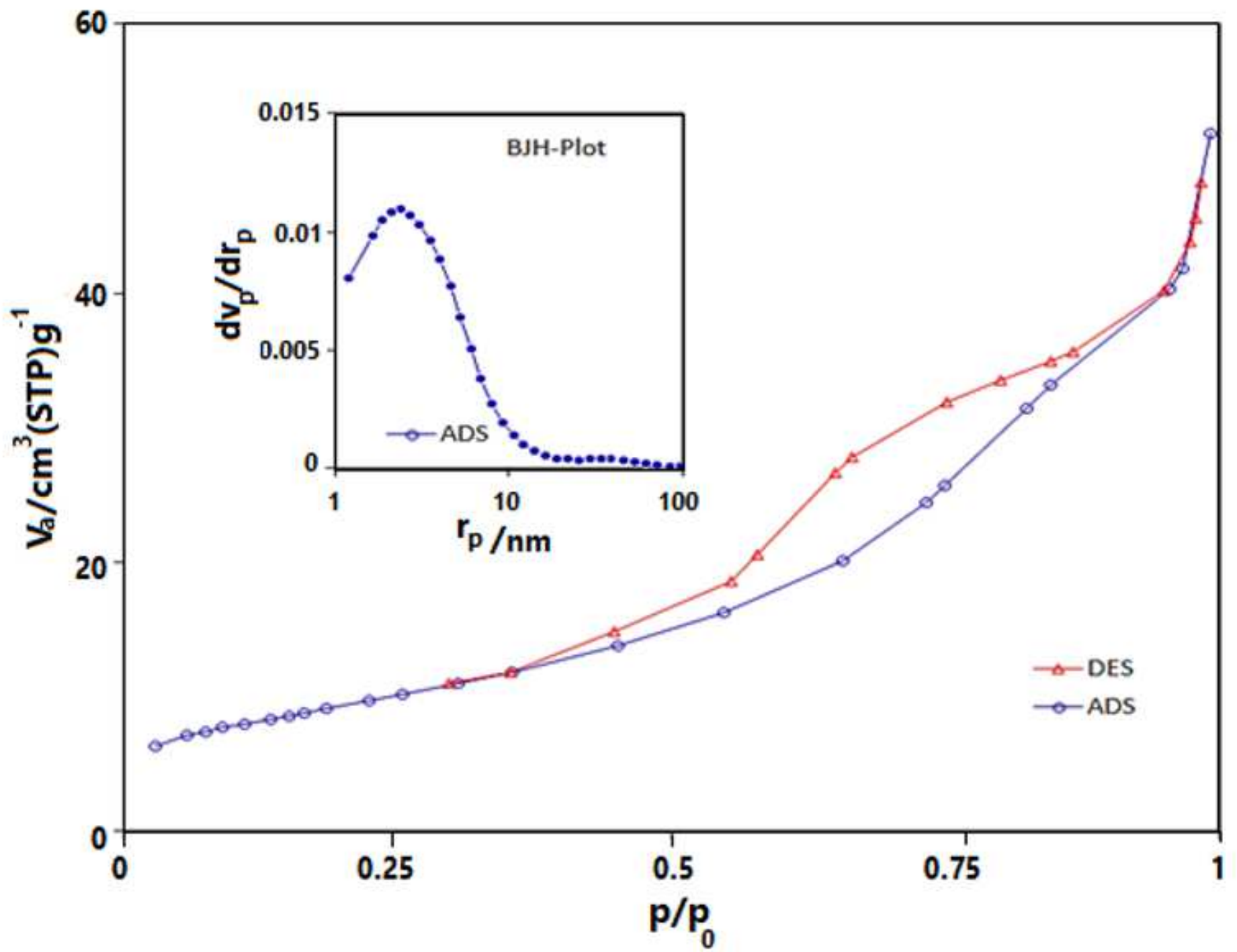

Figure 6

$\mathrm{N} 2$ adsorption-desorption isotherm of the biosynthesized CeO2-NPs. The inset figure is the pore radius distribution of $\mathrm{CeO} 2-\mathrm{NPs}$ 


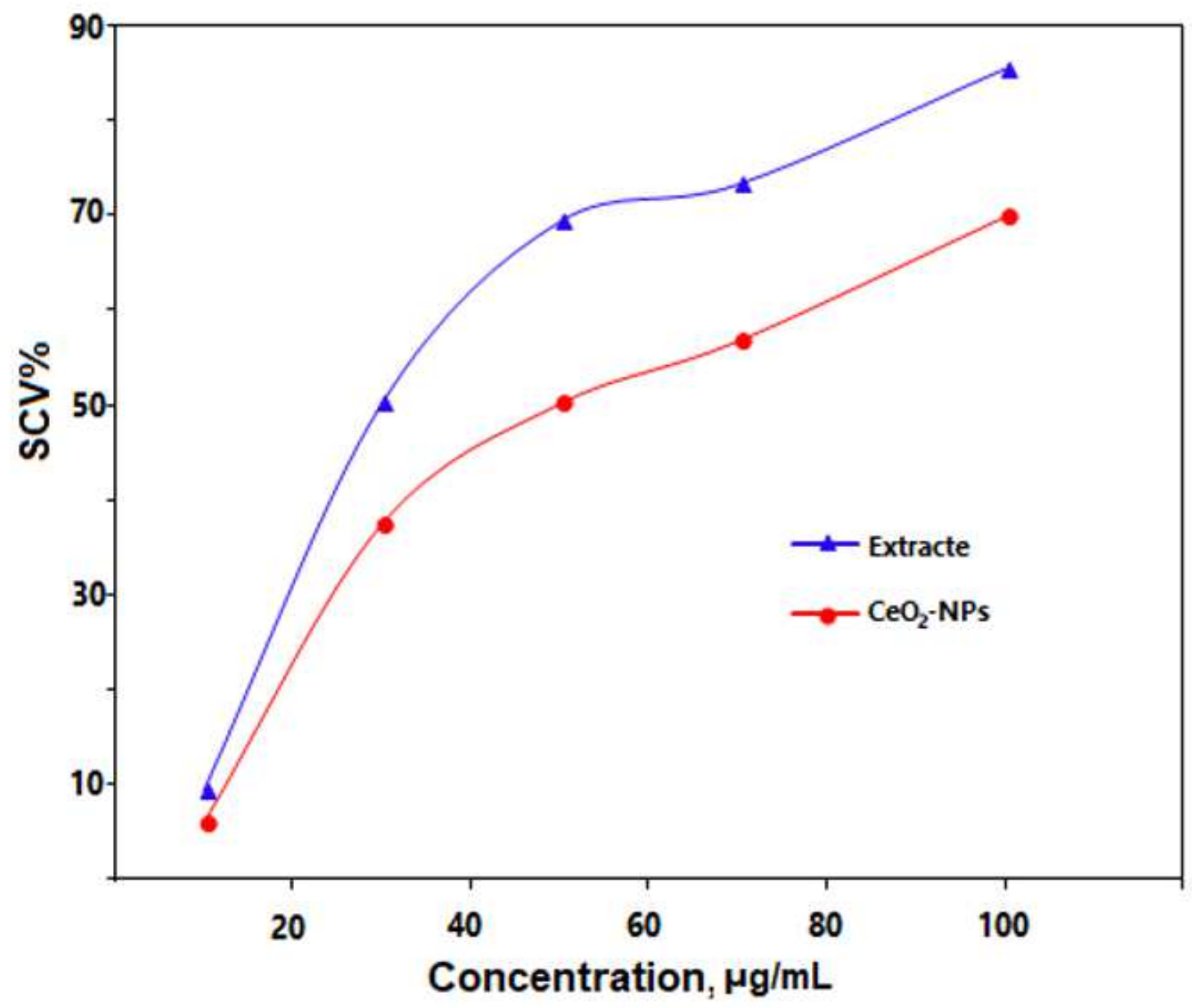

Figure 7

A comparison the antioxidant potential of the Pelargonium extract and biosynthesized CeO2-NPs 


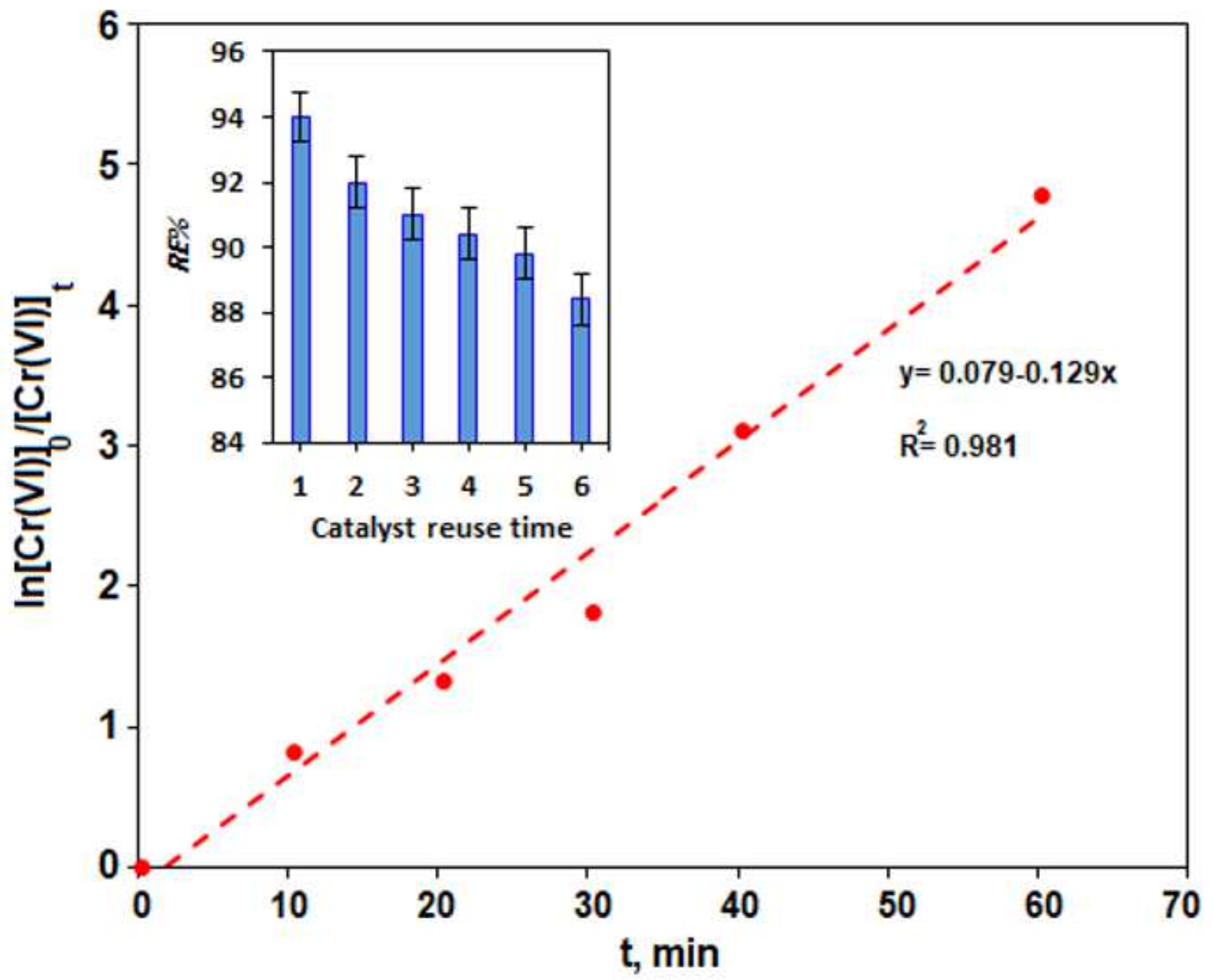

Figure 8

The kinetic plot in photocatalytic reduction of $\mathrm{Cr}(\mathrm{VI})$ ions under: $[\mathrm{Cr}(\mathrm{VII})]=10 \mathrm{mg} / \mathrm{L}$, [CeO2-NPs] 200 $\mathrm{mg} / \mathrm{L}, \mathrm{pH}=5.5$ and $\mathrm{t}=60 \mathrm{~min}$. The inset figure is the reuse time results of biosynthesized CeO2-NPs catalyst 